\title{
Samambaias e licófitas de um remanescente de floresta paludosa no interior do Estado de São Paulo, Brasil ${ }^{1}$
}

\author{
Frederico Fregolente Faracco Mazziero ${ }^{2,4}$, (D) Natália Arias Galastri² e (D) Fabiana Regina Nonato ${ }^{3}$
}

Recebido: 25.07.2019; aceito: 15.05.2020

Como citar: Mazziero, F.F.F., Galastri, N.A. \& Nonato, F.R. 2020. Samambaias e licófitas de um remanescente de floresta paludosa no interior do Estado de São Paulo, Brasil. Hoehnea 47: e812019. http://dx.doi.org/10.1590/2236-8906-81/2019.

\begin{abstract}
Ferns and lycophytes from a remaining swamp forest in the interior of the State of São Paulo, Brazil). The present study aimed to inventory the ferns and lycophytes in a remnant of swamp forest in the municipality of Dois Córregos, São Paulo State, Brazil, and provide data about the guilds of life forms, geographic distribution, a key to identification of species and comments about the taxa. Fifty-four taxa were found in the area, including 51 species, one variety, one subspecies, and a putative hybrid. The most representative genera were Amauropelta, Meniscium, and Pleopeltis. Terrestrial and neotropical species were the most representatives with $75.9 \%$ and $44.4 \%$, respectively. Swamp forests also have a greater diversity when compared to semideciduous seasonal forests in the interior of the State probably due to the availability of water throughout the year. Thereby, these fragments are important to the conservation of ferns and lycophytes in the interior of São Paulo State and they must be preserved.
\end{abstract}

Keywords: Atlantic forest, Biodiversity, Ferns, Flora, Lycophyta

RESUMO - (Samambaias e licófitas de um remanescente de floresta paludosa no interior do Estado de São Paulo, Brasil). O objetivo do presente estudo foi inventariar as samambaias e licófitas de um fragmento de floresta paludosa, no Município de Dois Córregos, São Paulo, Brasil, além de fornecer dados sobre as guildas de formas de vida, distribuição geográfica, chave para identificação e comentários dos táxons. Foram encontrados 54 táxons, incluindo 51 espécies, uma variedade, uma subespécie e um suposto híbrido. Os gêneros mais representativos foram Amauropelta, Meniscium e Pleopeltis. As espécies herbáceas terrícolas e neotropicais foram as mais representativas com 75,9\% e 44,4\%, respectivamente. As florestas paludosas também apresentam uma alta diversidade de espécies quando comparadas com a floresta estacional semidecidual do interior do Estado, provavelmente devido à disponibilidade de água durante todo o ano. Desta maneira, fica evidente a importância destes remanescentes na conservação das samambaias e licófitas no interior do Estado de São Paulo e, por isso, devem ser preservados.

Palavras-chave: Biodiversidade, Flora, Floresta Atlântica, Lycophyta, Samambaias

\section{Introdução}

Florestas paludosas são caracterizadas principalmente pelo afloramento do lençol freático, praticamente durante o ano todo, sendo marcante a presença de solos hidromórficos (Torres et al. 1994, Ivanauskas et al. 1997). Apesar dos estudos neste tipo de formação terem se intensificado nos últimos anos, principalmente na região Sudeste do país (e.g., Torres et al. 1994, Ivanauskas et al. 1997, Toniato et al. 1998, Paschoal \& Cavassan 1999, Teixeira \& Assis 2005, 2009, 2011, Marques et al. 2003, Scarano et al. 1997, 1998, Scarano 2006), estes são dedicados ao conhecimento da diversidade e estrutura das angiospermas.

1. Parte do Trabalho de Conclusão de Curso do primeiro Autor

2. Faculdade de Tecnologia de Jahu, Departamento de Meio Ambiente e Recursos Hídricos, Rua Frei Galvão, s.n., Jardim Pedro Ometto, 17212-599 Jaú, SP, Brasil

3. Universidade Estadual de Campinas, Divisão de Farmacologia e Toxicologia, Centro Pluridisciplinar de Pesquisas Químicas, Biológicas e Agrícolas, Rua Alexandre Calezatto, 999, Vila Betel, 13148-218 Paulínia, SP, Brasil

4. Autor para correspondência: fredericobio2@gmail.com 
Por sua vez, outros grupos de plantas, como samambaias e licófitas, são ainda pouco conhecidos em florestas paludosas. Trabalhos desenvolvidos nestas áreas, com estas plantas, estão geralmente associados com a amostragem de outros tipos de fitofisionomias, como floresta estacional semidecidual ou cerrado. Dentre eles, destacam-se Salino \& Joly (2001) para a bacia do Rio Jacaré-Pepira, Nóbrega \& Prado (2008) para o Jardim Botânico Municipal de Bauru e Mazziero \& Nonato (2015) para o Município de Jaú. Portanto, estudos realizados neste tipo de fitofisionomia, exclusivamente com samambaias e licófitas, tornam-se relevantes uma vez que a água é importante na distribuição e diversidade destes grupos de plantas (Poulsen 1996), sendo também um elemento fundamental para seu ciclo de vida (Windisch 1992a).

No Estado de São Paulo são registradas aproximadamente 618 espécies de samambaias e licófitas (Prado et al. 2015), com diversidade mais elevada nas regiões de Mata Atlântica litorâneas, mas também com uma expressiva representatividade em áreas do interior do Estado (Prado 1998, Prado \& Hirai 2011). Para as regiões de Mata Atlântica com predomínio de floresta ombrófila densa do Estado, destacam-se os estudos de Athayde-Filho et al. (2003), Boldrin \& Prado (2007), Mazziero et al. (2015), Nóbrega et al. (2016), Prado \& Labiak (2009), Salino \& Almeida (2008). Já para o interior paulista, nos cerrados, florestas estacionais e paludosas, pode-se citar: Colli et al. (2003, 2004a,b, 2007), Mazziero \& Nonato (2015), Nóbrega \& Prado (2008), Pietrobom et al. (2012), Salino (1996) e Salino \& Joly (2001). Mesmo o Estado de São Paulo sendo bem estudado, ainda são observadas novas ocorrências de espécies em áreas de vegetação nativa (e.g., Salino 1996, Nóbrega \& Prado 2008, Biral \& Prado 2012), evidenciando sua importância na preservação e conservação de samambaias e licófitas.

Diante disso, o objetivo do presente estudo foi caracterizar a flora de samambaias e licófitas em um remanescente de floresta paludosa no interior do Estado de São Paulo, apresentando uma chave para a identificação das espécies, comentários sobre as guildas de formas de vida e distribuição geográfica de cada táxon.

\section{Materiais e Métodos}

O presente estudo foi realizado em um remanescente de 23,5 ha de floresta paludosa no Município de Dois Córregos, São Paulo, na porção central do Estado, nas coordenadas geográficas de $22^{\circ} 23^{\prime} 44^{\prime \prime} \mathrm{S}$ e $48^{\circ} 16^{\prime} 69^{\prime} \mathrm{O}$ (figura 1). Este remanescente constitui uma Área de Preservação Permanente (APP) de duas nascentes do Riberão do Bugio, localizadas em uma propriedade particular, denominada Pesqueiro Jussara.

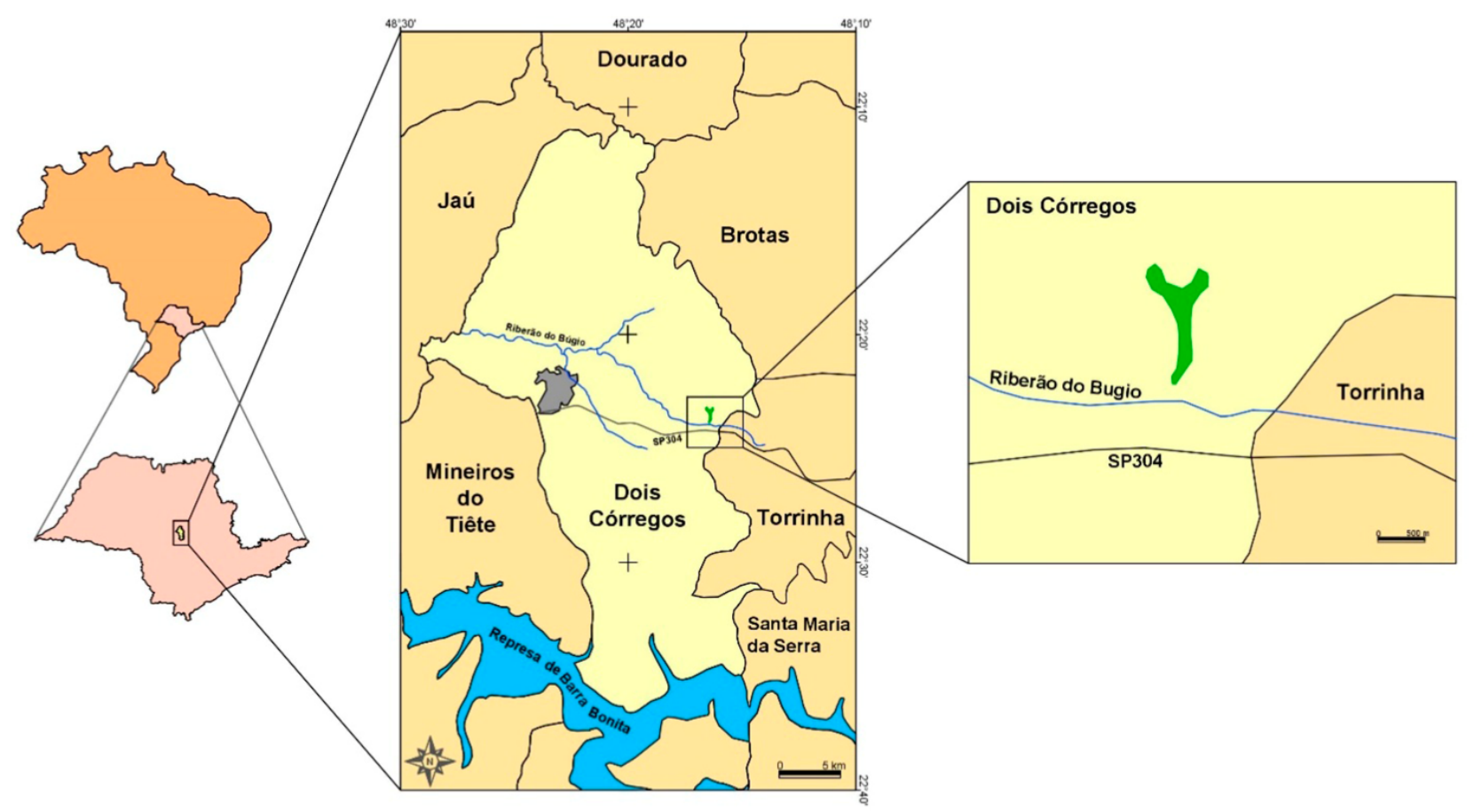

Figura 1. Mapa de localização da área de estudo no Município de Dois Córregos, Estado de São Paulo, Brasil.

Figure 1. Location map of the study area in the Dois Córregos Municipality, São Paulo State, Brazil. 
Apesar da maior parte da floresta se encontrar em terreno plano e solo encharcado, a porção próxima a borda encontra-se mais elevada, apresentando o solo seco. Desta maneira, são observadas diferenças na composição e estrutura florestal em comparação com o restante do remanescente. Nestas áreas mais elevadas o dossel não é contínuo, as árvores variam de 4-6 metros de altura, não havendo a formação de um sub-bosque, além disso, em alguns pontos há o predomínio de Urochloa sp. (braquiária). As espécies arbustivo-arbóreas mais comuns são: Byrsonima intermedia A. Juss. (murici), Myrcia guianensis (Aubl.) DC. (araçazinho), Myrcia multiflora (Lam.) DC. (cambuí), Stryphnodendron adstringens (Mart.) Coville (barbatimão) e Styrax pohlii A. DC. (benjoeiro). Nos trechos onde o solo se encontra encharcado o dossel é fechado, as árvores variam entre 10 e 12 metros, com algumas atingindo 14-15 metros de altura (figura $2 \mathrm{a}-\mathrm{d}$ ). As espécies de árvores mais comuns são Calophyllum brasiliense Cambess. (guanandi), Euterpe edulis Mart. (palmito-juçara), Magnolia ovata (A.St.-Hil.) Spreng. (pinha-do-brejo), Protium spruceanum (Benth.) Engl. (almecéga-do-brejo) e Tapirira guianensis Aubl. (peito-de-pombo).
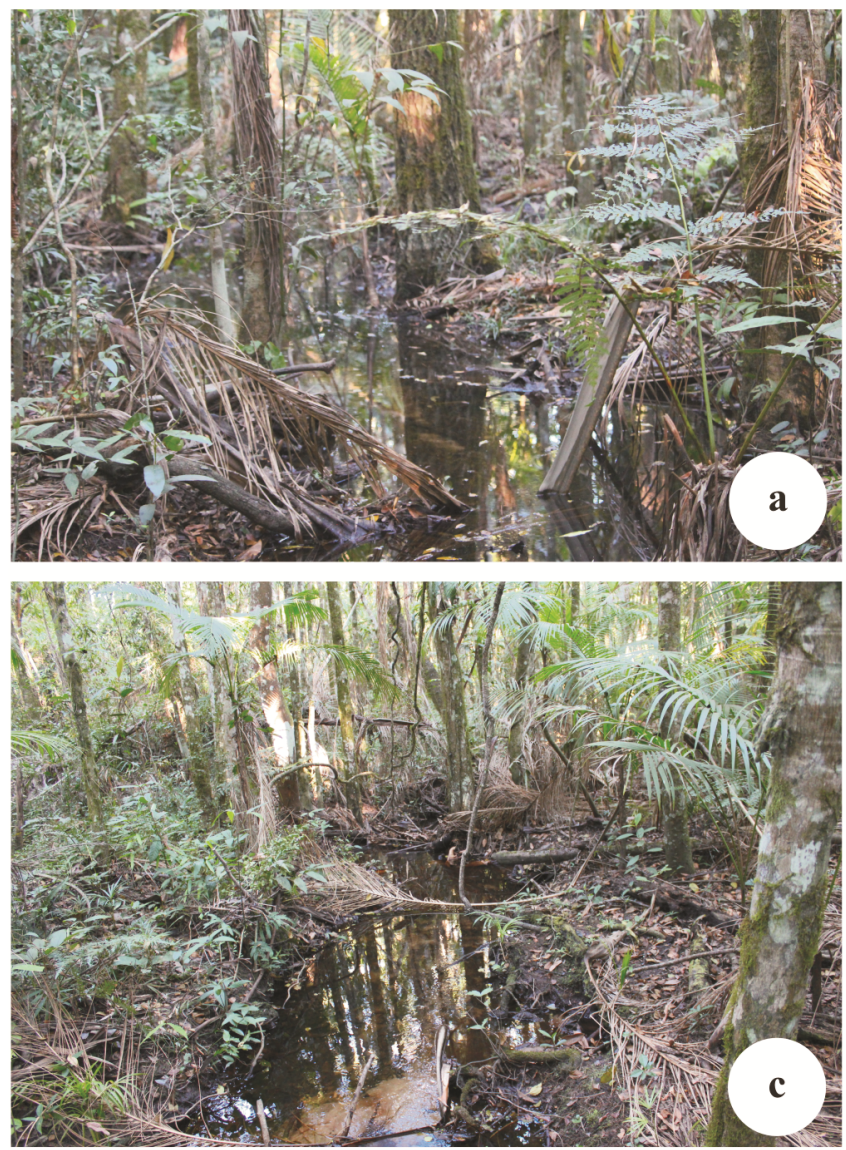

A altitude média do município é de $667 \mathrm{~m}$, com clima enquadrado como "Cfa" seguindo os critérios de Köppen (Alvares et al. 2014). A temperatura e precipitação média anuais são de $19,8^{\circ} \mathrm{C}$ e $1311 \mathrm{~mm}$, respectivamente (ClimateData 2019). As coletas foram realizadas mensalmente durante o primeiro semestre de 2014, adotando-se o método do caminhamento proposto por Filgueiras et al. (1994). O mapa de localização do remanescente foi elaborado a partir do mapa de Dois Córregos disponível em SIFESP (2009).

Os exemplares amostrados foram herborizados de acordo com as técnicas propostas por Windisch (1992a) e depositados no herbário BAUR da Universidade do Sagrado Coração no Município de Bauru, SP. O sistema de classificação adotado foi o proposto por PPG I (2016). Foram averiguadas as guildas de formas de vida seguindo o proposto por Paciencia (2008). A ocorrência das espécies em países americanos ou em outros continentes foi verificada a partir de literatura específica para cada grupo. A distribuição das espécies no Brasil seguiu o proposto na Flora do Brasil (2020 in prep.).
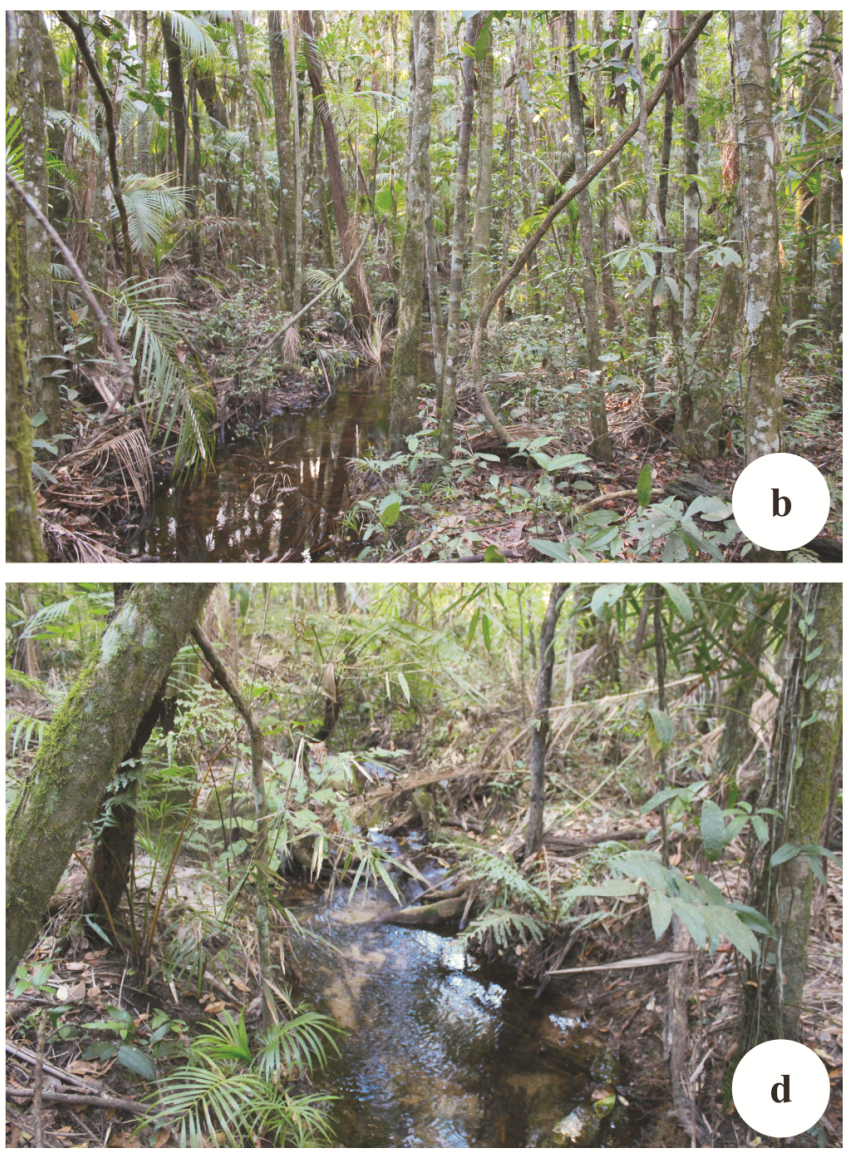

Figura 2. Área de estudo no Município de Dois Córregos, Estado de São Paulo, Brasil. a-d. vista do interior da floresta paludosa.

Figure 2. Study area in Dois Córregos Municipality, São Paulo State, Brazil. a-d. interior views of swamp forest. 


\section{Resultados e discussão}

Foram registrados no presente estudo 53 táxons de samambaias, sendo 50 espécies, uma variedade, uma subespécie e um híbrido (Pityrogramma calomelanos
(L.) Link x P. trifoliata (L.) R.M. Tryon). Além disso, foi encontrada uma espécie de licófita (Palhinhaea cernua (L.) Franco \& Vasc.).

Chave para a identificação das espécies de samambaias e licófitas da área de estudo

1. Plantas com microfilos (folhas apenas com uma nervura)

36. Palhinhaea cernua

1. Plantas com megafilos (folhas com várias nervuras)

2. Plantas aquáticas, flutuantes

47. Salvinia auriculata

2. Plantas terrícolas ou epífitas

3. Soros em esporangióforos na margem ou no ápice da lâmina

4. Ervas; esporângios dispostos em 5-6-esporangióforos no ápice da fronde

1. Actinostachys subtrijuga

4. Trepadeiras; esporângios dispostos em projeções na margem da lâmina 25. Lygodium volubile

3. Soros abaxiais ou nas margens dos segmentos/pinas, nunca em projeções

5. Frondes dimorfas ou hemidimorfas

6. Lâmina inteira

7. Frondes até $10 \mathrm{~cm}$ de comprimento; soros arredondados

32. Microgramma squamulosa

7. Frondes maiores que $12 \mathrm{~cm}$ de comprimento; soros acrosticoides

8. Caule curto-reptante, pecíolos com até $1 \mathrm{~cm}$ de distância uns dos outros; lâmina oblanceolada

17. Elaphoglossum luridum

8. Caule longo-reptante, pecíolos com 4-5(8) cm de distância uns dos outros; lâmina lanceolada

18. Elaphoglossum vagans

6. Lâmina 1-pinada ou 2-pinada

9. Frondes hemidimorfas, lâmina estéril 2-pinada

34. Osmunda spectabilis

9. Frondes dimorfas, lâmina estéril 1-pinada a 1-pinado-pinatissecta

10. Lâmina estéril 1-pinado-pinatissecta

35. Osmundastrum cinnamomeum

10. Lâmina estéril 1-pinada

11. Lâmina estéril com nervuras anastomosadas

13. Cyclodium meniscioides

11. Lâmina estéril com nervuras livres

12. Caule ereto; pinas basais gradualmente reduzidas

24. Lomariocycas schomburgkii

12. Caule decumbente a curto-reptante; pinas basais não reduzidas

37. Parablechnum cordatum

5. Frondes monomorfas

13. Pecíolo com acúleos ou espinhos

14. Caule longo-reptante; soros marginais

19. Hypolepis repens

14. Caule ereto, arborescente; soros abaxiais

15. Soros com indúsio

12. Cyathea delgadoi

15. Soros sem indúsio

11. Cyathea atrovirens

13. Pecíolo inerme

16. Lâmina com uma camada de células de espessura

17. Plantas terrícolas; lâmina 1-pinada

53. Trichomanes cristatum

17. Plantas epífitas; lâmina pinatissecta

18. Venação catádroma; soros no ápice dos segmentos

54. Trichomanes polypodioides

18. Venação anádroma; soros na axila dos segmentos

52. Trichomanes anadromum

16. Lâmina com duas ou mais camadas de células de espessura 
19. Lâmina pseudodicotomicamente dividida

20. Gemas protegidas por tricomas 16. Dicranopteris flexuosa

20. Gemas protegidas por escamas 51. Sticherus lanuginosus

19. Lâmina nunca pseudodicotomicamente dividida

21. Soros marginais

22. Caule revestido apenas por tricomas

46. Pteridium esculentum

22. Caule revestido por escamas e tricomas

23. Lâmina pedada; soros protegidos pela margem recurvada da lâmina (pseudoindúsio)

26. Lytoneuron lomariaceum

23. Lâmina 1-pinada ou 2-pinada, nunca pedada; soros protegidos por indúsio verdadeiro

24. Raque cilíndrica em corte transversal

21. Lindsaea divaricata

24. Raque quadrangular em corte transversal

25. Pecíolo nigrescente em toda a sua extensão

23. Lindsaea quadrangularis subsp. terminalis

25. Pecíolo paleáceo ao menos nas porções medianas e distais

22. Lindsaea lancea var. lancea

21. Soros abaxiais

26. Face abaxial da lâmina coberta por substância cerosa branca

27. Pinas distais inteiras e oblongas

41. Pityrogramma trifoliata

27. Pinas distais pinatífidas e deltoides 39. Pityrogramma calomelanos

26. Face abaxial desprovida de substância cerosa branca

28. Lâmina inteira

29. Duas ou mais fileiras de soros entre a nervura mediana e a margem da lâmina; soros arredondados

8. Campyloneurum nitidum

29. Uma fileira de soros entre a nervura mediana e a margem da lâmina; soros oblongos

Lâmina pinatissecta até 3-pinado-pinatissecta

30. Soros lineares a oblongos, indúsio presente

31. Soros perpendiculares e não adjacentes à costa

15. Deparia petersenii

31. Soros paralelos e adjacentes à costa

32. Caule ereto (subarborescente); base da lâmina pinatissecta, gradualmente reduzida

33. Neoblechnum brasiliense

32. Caule ereto a decumbente, nunca subarborescente; base da lâmina 1-pinada, truncada

7. Blechnum occidentale

30. Soros arredondados ou elípticos, se lineares, arqueados e desprovidos de indúsio

33. Frondes articuladas ao caule, filopódio presente

34. Lâmina 1-pinada na base

35. Caule curto-reptante; faces abaxial e adaxial da lâmina conspicuamente escamosas

43. Pleopeltis hirsutissima

35. Caule longo-reptante; faces abaxial e adaxial da lâmina sem escamas ou com escamas esparsas e inconspícuas

49. Serpocaulon fraxinifolium

34. Lâmina inteiramente pinatissecta

36. Segmentos ascendentes, cerca de $45^{\circ}$ em relação à raque 45. Pleopeltis pleopeltifolia

36. Segmentos patentes, cerca de $90^{\circ}$ em relação à raque

37. Caule com depósitos de substância cerosa branca 48. Serpocaulon catharinae

37. Caule desprovido de depósitos de substância cerosa branca

38. Frondes com até $12 \mathrm{~cm}$ de comprimento; faces abaxial e adaxial conspicuamente escamosas ....... 44. Pleopeltis minima 
38. Frondes maiores que $30 \mathrm{~cm}$ de comprimento; faces abaxial e adaxial desprovidas de escamas ou com escamas esparsas e inconspícuas

39. Nervuras livres 38. Pecluma robusta

39. Nervuras anastomosadas 50. Serpocaulon vacillans

33. Frondes não articuladas ao caule, filopódio ausente

40. Lâmina 3-pinado-pinatissecta

41. Base do pecíolo com 1, 3 ou mais feixes vasculares

20. Lastreopsis amplissima

41. Base do pecíolo com 2 feixes vasculares

27. Macrothelypteris torresiana

40. Lâmina 1-pinada a 1-pinado-pinatissecta

42. Lâmina 1-pinada

43. Margem da pina serreada

31. Meniscium serratum

43. Margem da pina inteira ou crenulada

44. Pinas ovais a elípticas

29. Meniscium chrysodioides

44. Pinas lanceoladas a oblongas

45. Pinas proximais oblongas a levemente lanceoladas, com a base cuneada

30. Meniscium longifolium

45. Pinas proximais lanceoladas a elípticas, com a base arredondada a truncada

28. Meniscium arborescens

42. Lâmina 1-pinado-pinatífida a 1-pinado-pinatissecta

46. Base da lâmina com 2-10 pares de pinas gradualmente reduzidos

47. Caule longo-reptante

6. Amauropelta rivularioides

47. Caule ereto a decumbente

48. Gemas presentes na porção distal da lâmina

2. Amauropelta amambayensis

48. Gemas ausentes

49. Cápsula do esporângio com tricomas setosos

3. Amauropelta heineri

49. Cápsula do esporângio glabra

50. Aeróforos presentes na base das pinas

5. Amauropelta pachyrhachis

50. Aeróforos ausentes

4. Amauropelta opposita

46. Base da lâmina sem pinas reduzidas, às vezes com 1-2 pares levemente menores que os imediatamente acima

51. Caule longo-reptante, nigrescente

14. Cyclosorus interruptus

51. Caule ereto a decumbente, nunca nigrescente

52. Pecíolo purpúreo; nervuras de segmentos adjacentes unindo-se em uma nervura excurrente ...... 10. Christella dentata

52. Pecíolo castanho; nervuras de segmentos adjacentes unindo-se diretamente ao enseio

9. Christella conspersa

1. Actinostachys subtrijuga (Mart.) C. Presl (Schizaeaceae)

Espécie facilmente reconhecida, dentre as observadas na área de estudo, por apresentar frondes inteiras, extremamente estreitas com 0,3-0,4 mm de largura. Além disso, apresenta soros agrupados em 5-6 esporangióforos, digitados, no ápice da fronde.

Espécie terrícola, encontrada no interior da floresta em locais sombreados e com solo encharcado, próximos a riachos. Ocorre na Colômbia, Guiana Francesa, Suriname, Venezuela e no Brasil: AC, AM, BA, PA, PB, PE, PR, RO,
RR e SP (Silva et al. 2015, Santiago \& Almeida 2020 in prep.).

Material examinado: F.F.F. Mazziero 1739 (BAUR).

2. Amauropelta amambayensis (Ponce) Salino \& T.E. Almeida (Thelypteridaceae)

Única espécie do gênero, encontrada na área de estudo, que apresenta gema na porção distal da lâmina, soros desprovidos de indúsio e, ao menos os proximais, elípticos, 
além de tricomas uncinados presentes no pecíolo, raque, costa abaxial e escamas da base do pecíolo.

Espécie terrícola, encontrada no interior da floresta, em locais sombreados e solo encharcado, às margens de regatos ou nos pontos de inundação. Pode ser encontrada na Argentina, Paraguai e no Brasil: ES, MG, PR, RJ, RS, SC e SP (Salino \& Semir 2004a, Ponce 2007).

Material examinado: F.F.F. Mazziero 1741 (BAUR).

3. Amauropelta heineri (C. Chr.) Salino \& T.E. Almeida (Thelypteridaceae)

Separa-se das demais espécies observadas na área de estudo principalmente pela presença de esporângios setosos e ausência de tricomas glandulares, presentes em Amauropelta opposita e A. pachyrhachis.

Espécie terrícola, encontrada no interior da floresta, em locais de solo encharcado. Espécie com ocorrência restrita ao Brasil: DF, GO, MG, MS e SP (Ponce 2007).

Material examinado: F.F.F. Mazziero s.n. (BAUR).

4. Amauropelta opposita (Vahl) Pic. Serm. (Thelypteridaceae)

Assemelha-se a Amauropelta pachyrhachis, no entanto, o tecido laminar abaxial apresenta tricomas setiformes, além de não apresentar aeróforos e escamas costais na face abaxial das pinas.

Espécie terrícola, encontrada em locais alterados, como a borda ou clareiras no interior da floresta, em pontos com solo encharcado e ensolarado. Ocorre nas Antilhas, Costa Rica, Panamá, Venezuela, Colômbia, Equador, Peru, Bolívia, Paraguai e no Brasil: AC, BA, DF, ES, GO, MG, MS, MT, PR, RJ, RO, RS, SC, SP e TO (Smith 1992, Salino \& Semir 2004a, Ponce 2007).

Material examinado: F.F.F. Mazziero 1776 (BAUR).

5. Amauropelta pachyrhachis (Kunze ex Mett.) Salino \& T.E. Almeida (Thelypteridaceae)

Figura 3 a

Dentre as espécies do gênero observadas na área de estudo, Amauropelta pachyrhachis é semelhante a $A$. opposita, sendo reconhecida pelo tecido laminar abaxial desprovido de tricomas setiformes, além de apresentar aeróforos na base das pinas e escamas costais.

Espécie terrícola, encontrada nos pontos mais altos da área de estudo, crescendo a pleno sol e solo seco, na borda da floresta. Encontrada nas Antilhas, Costa Rica, Panamá, Venezuela, Colômbia, Peru, Bolívia, Paraguai, Argentina e no Brasil: DF, ES, GO, MG, PR, RJ, RS, SC e SP (Ponce 1995, 2007, Salino \& Semir 2004a).

Material examinado: F.F.F. Mazziero 2001 (BAUR).

6. Amauropelta rivularioides (Fée) Salino \& T.E. Almeida (Thelypteridaceae)

Figura $3 \mathrm{~b}$
Facilmente separada das espécies de Amauropelta encontradas na área de estudo pelo caule longo-reptante e tricomas setiformes pluricelulares presentes na raque.

Espécie terrícola, encontrada na borda da floresta em locais sombreados ou a pleno sol, em solo encharcado. Citada para Argentina, Bolívia, Paraguai, Uruguai e no Brasil: BA, DF, ES, GO, MG, MT, PR, RJ, RS, SC e SP (Ponce 1995, Smith \& Kessler 2017).

Material examinado: F.F.F. Mazziero 1773 (BAUR).

\section{Blechnum occidentale L. (Blechnaceae)}

Separa-se das espécies da família Blechnaceae encontradas na área pelo caule ereto, mas nunca subarborescente, as escamas da base do pecíolo são deltoides e castanho-claras, frondes monomorfas e base da lâmina truncada, com o par basal de pinas não adnato a raque.

Espécie terrícola, encontrada nos pontos mais altos, sombreados e com solo seco, no interior da floresta. Ocorre nos Estados Unidos, México, Guatemala, Belize, Honduras, El Salvador, Nicarágua, Costa Rica, Panamá, Antilhas, Guiana, Suriname, Guiana Francesa, Colômbia, Venezuela, Equador, Peru, Bolívia, Chile, Paraguai e Argentina. No Brasil ocorre em: AC, AM, BA, CE, DF, ES, GO, MT, MG, MS, PA, PR, PE, RJ, RR, RS, SE, SC e SP (Dittrich et al. 2015).

Material examinado: F.F.F. Mazziero 1774 (BAUR).

8. Campyloneurum nitidum (Kaulf.) C. Presl (Polypodiaceae)

Pode ser reconhecida dentre as demais espécies com lâmina inteira observadas na área, pela fronde monomorfa com 4-5(6) fileiras de soros entre a costa e a margem da lâmina.

Espécie terrícola, encontrada no interior da floresta em locais sombreados e solo encharcado, às margens de regatos. Ocorre na Argentina, Paraguai, Uruguai e no Brasil: BA, ES, MG, PR, RJ, RS, SC e SP (Prado et al. 2010).

Material examinado: F.F.F. Mazziero 1768 (BAUR).

9. Christella conspersa (Schrad.) Á. Löve \& D. Löve (Thelypteridaceae)

Espécie semelhante a Christella dentata, no entanto, apresenta o pecíolo castanho-escuro e nervuras basais de segmentos adjacentes atingindo diretamente o enseio ou unindo-se em um ângulo agudo e formando uma nervura excurrente curta, com até $0,5 \mathrm{~mm}$ de comprimento.

Espécie terrícola. Cresce entre gramíneas na borda da floresta, a pleno sol e em solo seco ou úmido. Pode ser encontrada no Panamá, Colômbia, Venezuela, Equador, Peru, Bolívia, Paraguai, Uruguai e no Brasil: BA, DF, ES, GO, MG, MS, MT, PE, PR, RJ, RS, SC e SP (Smith 1992, Ponce et al. 2013).

Material examinado: F.F.F. Mazziero 2002 (BAUR). 

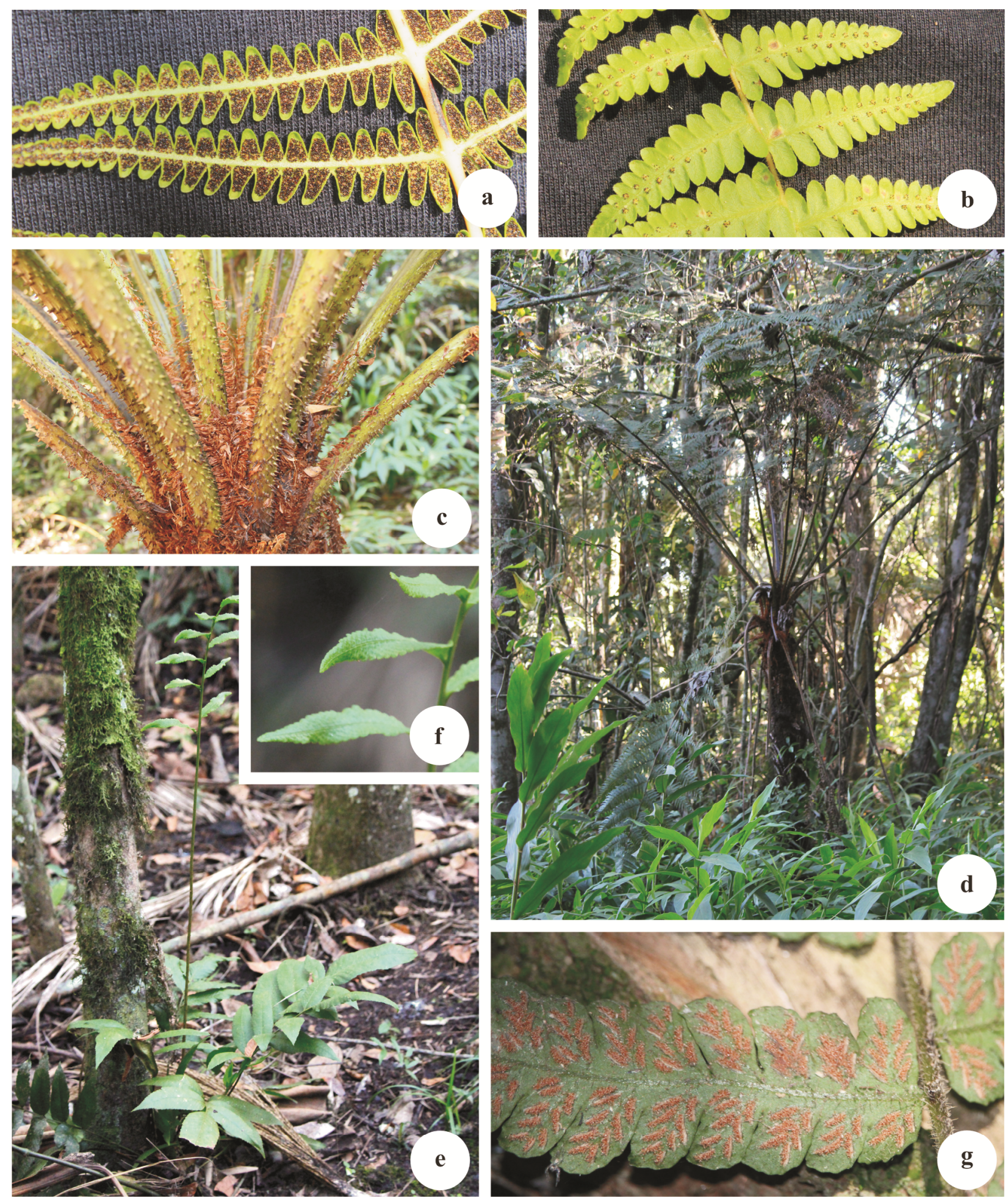

Figura 3. Espécies encontradas em área de floresta paludosa no Município de Dois Córregos, Estado de São Paulo, Brasil. a. Amauropelta pachyrhachys (Kunze ex Mett.) Salino \& T.E. Almeida. a. superfície abaxial. b. Amauropelta rivularioides (Fée) Salino \& T.E. Almeida. b. superfície abaxial. c-d. Cyathea atrovirens (Langsd. \& Fisch.) Domin. c. base dos pecíolos. d. hábito. e-f. Cyclodium meniscioides (Willd.) C. Presl. e. hábito. f. detalhe da fronde fértil. g. Deparia petersenii (Kunze) M. Kato. g. superfície abaxial.

Figure 3. Species found in a swamp forest area in Dois Córregos Municipality, São Paulo State, Brazil. a. Amauropelta pachyrhachys (Kunze ex Mett.) Salino \& T.E. Almeida. a. abaxial surface. b. Amauropelta rivularioides (Fée) Salino \& T.E. Almeida. b. abaxial surface. c-d. Cyathea atrovirens (Langsd. \& Fisch.) Domin. c. petioles bases. d. habit. e-f. Cyclodium meniscioides (Willd.) C. Presl. e. habit. f. fertile frond detail. g. Deparia petersenii (Kunze) M. Kato. g. abaxial surface. 
10. Christella dentata (Forssk.) Brownsey \& Jermy (Thelypteridaceae)

Difere das espécies do gênero observadas na área de estudo pelo pecíolo purpúreo, ao menos na porção proximal, e suas nervuras basais de segmentos adjacentes sempre se unem em um ângulo reto, formando uma nervura excurrente longa, com $1 \mathrm{~mm}$ ou mais.

Espécie terrícola, encontrada em locais alterados como bordas e clareiras, geralmente entre gramíneas em locais ensolarados com solo seco a úmido. Espécie introduzida na região neotropical, sendo encontrada nos Estados Unidos, México até Chile, Uruguai e no Brasil: AL, BA, CE, DF, ES, GO, MA, MG, MS, MT, PA, PB, PE, PR, RJ, RO, RS, SC e SP (Smith 1992, Ponce et al. 2013).

Material examinado: F.F.F. Mazziero 1780 (BAUR).

11. Cyathea atrovirens (Langsd. \& Fisch.) Domin (Cyatheaceae)

Figura $3 \mathrm{c}-\mathrm{d}$

Separa-se de Cyathea delgadoi, a outra espécie do gênero encontrada na área, pela ausência de indúsio e pelas bases dos pecíolos permanecerem fixas ao caule após a queda da folha.

Espécie arborescente, encontrada na borda do fragmento crescendo a pleno sol ou em ambientes sombreados e úmidos no interior da floresta. Ocorre na Argentina, Paraguai, Uruguai e no Brasil: BA, ES, GO, MG, PE, PR, RJ, RS, SC e SP (Lehnert 2016, Weigand \& Lehnert 2016).

Material examinado: F.F.F. Mazziero 1729 (BAUR).

12. Cyathea delgadoi Pohl ex Sternb. (Cyatheaceae)

Pode ser reconhecida pela presença de indúsio, além disso, as bases dos pecíolos não permanecem fixas após a queda da folha, deixando uma cicatriz no caule.

Espécie arborescente, encontrada no interior da floresta em locais úmidos ou em pontos mais secos próximos a borda do remanescente. Distribui-se da Costa-Rica até o Panamá e da Venezuela até a Bolívia, no Brasil: AC, AM, BA, CE, DF, ES, GO, MG, MS, MT, PE, PI, PR, RJ, RO, RR, RS, SC e SP (Weigand \& Lehnert 2016, Lehnert \& Kessler 2018).

Material examinado: F.F.F. Mazziero 1731 (BAUR).

\section{Cyclodium meniscioides (Willd.) C. Pres1}

(Dryopteridaceae)

Figura 3 e-f

Dentre as espécies observadas na área de estudo com frondes dimorfas, Cyclodium meniscioides pode ser reconhecida por apresentar nervuras anastomosadas nas pinas estéreis. Além disso, a fronde fértil apresenta tecido lâminar e os soros são arredondados com indúsio.

Espécie terrícola, encontrada próxima às margens de córregos, nas áreas sujeitas a alagamento e em locais sombreados no interior da floresta. Cyclodium meniscioides ocorre em Trinidad, Colômbia, Venezuela, Suriname, Guiana, Equador, Peru, Bolívia, Argentina, Paraguai e no Brasil: AC, AM, AP, BA, CE, DF, ES, GO, MT, PA, PI, RO e SP (Smith 1986).

Material examinado: F.F.F. Mazziero 1782 (BAUR).

14. Cyclosorus interruptus (Willd.) H. Itô (Thelypteridaceae)

Diferencia-se facilmente das demais espécies da família Thelypteridaceae observadas na área de estudo por apresentar caule longo-reptante, com escamas esparsas, base da lâmina truncada e escamas presentes na superfície abaxial das pinas.

Espécie terrícola, encontrada em pontos encharcados na borda da floresta, a pleno sol e entre gramíneas. Espécie pantropical, sendo encontrada no continente americano nos Estados Unidos, México, Caribe até Panamá, Colômbia, Guiana até Bolívia, Argentina, Paraguai, Uruguai e no Brasil: $\mathrm{AL}, \mathrm{AM}, \mathrm{AP}, \mathrm{BA}, \mathrm{CE}, \mathrm{DF}, \mathrm{ES}, \mathrm{GO}, \mathrm{MA}, \mathrm{MG}, \mathrm{MS}, \mathrm{MT}, \mathrm{PB}$, PE, PR, RJ, RS, SC e SP (Smith 1992, Ponce et al. 2013).

Material examinado: F.F.F. Mazziero 1792 (BAUR).

\section{Deparia petersenii (Kunze) M. Kato (Athyriaceae)}

Figura $3 \mathrm{~g}$

Separa-se das demais espécies encontradas na área pela presença de soros oblongos e perpendiculares a costa.

Espécie terrícola, encontrada na borda da floresta ou em clareiras, crescendo a pleno sol ou em locais sombreados, sempre com o solo encharcado. Espécie com ocorrência na América do Norte, do Sul, Ásia e introduzida no Brasil: ES, MG, PE, PR, RJ, RS, SC e SP (Mynssen 2011).

Material examinado: F.F.F. Mazziero 1747 (BAUR).

\section{Dicranopteris flexuosa (Schrad.) Underw.}

(Gleicheniaceae)

Dentre as espécies observadas no presente estudo, pertencentes à família Gleicheniaceae, Dicranopteris flexuosa pode ser reconhecida por apresentar pinas acessórias na base das bifurcações, gemas das bifurcações protegidas por tricomas e superfície abaxial dos segmentos glabra.

Espécie terrícola, encontrada na borda da floresta crescendo junto a Sticherus lanuginosus, a pleno sol e solo seco. Espécie encontrada nos Estados Unidos, México, América Central, Antilhas, Colômbia, Venezuela, Guiana, Suriname, Guiana Francesa, Trinidad, Equador, Peru, Bolívia, Paraguai, Argentina e no Brasil: AL, BA, CE, AM, AP, DF, ES, GO, MA, MG, MS, MT, PA, PE, PB, PR, RJ, RN, RO, RR, RS, SC, SE, SP e TO (Lima \& Salino 2018).

Material examinado: F.F.F. Mazziero 1738 (BAUR).

17. Elaphoglossum luridum (Fée) Christ (Dryopteridaceae) Figura 4 a

Dentre as espécies de Elaphoglossum que ocorrem na área de estudo, esta espécie pode ser reconhecida por 
apresentar o caule curto-reptante, pecíolo atingindo, no máximo, 1/4 do tamanho da fronde, lâmina oblanceolada.

Espécie terrícola, encontrada em locais sombreados e com solo encharcado no interior da floresta. Ocorre nas Antilhas, da Costa-Rica até a Bolívia e no Brasil: AC, AM, AP, DF, ES, GO, MG, MS, MT, PA, PR, RJ, RO, RR, RS, SC, SP e TO (Mickel 1991, Kessler et al. 2018).

Material examinado: F.F.F. Mazziero 1736 (BAUR).

18. Elaphoglossum vagans (Mett.) Hieron. (Dryopteridaceae)

Espécie com caule longo-reptante, pecíolo com cerca de 1/3 a 1/2 do tamanho da fronde e lâmina lanceolada, diferindo de Elaphoglossum luridum que também foi registrada na área de estudo.

Espécie epífita, crescendo sobre angiospermas em locais sombreados no interior da floresta. Espécie endêmica do Brasil: BA, ES, GO, MG, PE, PR, RJ, RS, SC e SP.

Material examinado: F.F.F. Mazziero 1779 (BAUR).

\section{Hypolepis repens (L.) C. Presl (Dennstaedtiaceae)}

Trata-se da única espécie herbácea na área de estudo a apresentar acúleos no pecíolo e na raque, sendo esta característica observada também nas espécies da família Cyatheaceae, no entanto, estas são arborescentes. Além disso, em todas as espécies da área que apresentam soros marginais, esses são irrigados por duas ou mais nervuras, enquanto em Hypolepis repens o soro é irrigado por apenas uma.

Espécie terrícola, encontrada no interior da floresta, em local sombreado às margens dos córregos e também na borda do remanescente, em locais sombreados com solo encharcado. Ocorre nos Estados Unidos, Jamaica, Hispaniola, Porto Rico, Saint Christopher, Guadalupe, Dominica, Martinica, Santa Lúcia, Trinidad \& Tobago, México, Guatemala, Honduras, Costa Rica, Panamá, Colômbia, Venezuela, Guiana, Suriname, Guiana Francesa e no Brasil: AL, BA, CE, MG, MS, PA, PE, RJ e SP (Schwartsburd \& Prado 2016).

Material examinado: F.F.F. Mazziero 1766 (BAUR).

20. Lastreopsis amplissima (C. Presl) Tindale (Dryopteridaceae)

Espécie com três ou mais feixes vasculares na base do pecíolo e com a face adaxial da costa sulcada, diferindo assim de Macrothelypteris torresiana, a espécie mais semelhante pela divisão da lâmina, verificada na área de estudo.

Espécie terrícola, encontrada no interior da floresta, crescendo às margens dos cursos d'água. Ocorre na Venezuela, Guiana, Bolívia, Paraguai, Argentina e no Brasil: BA, ES, CE, DF, MG, PE, PR, RJ, RS, SC e SP (Hirai \& Prado 2012, Kessler et al. 2018).

Material examinado: F.F.F. Mazziero 1754 (BAUR).
21. Lindsaea divaricata Klotzsch (Lindsaeaceae)

Separa-se das demais espécies do gênero observadas na área de estudo pela raque abaxialmente cilíndrica e adaxialmente quadrangular, de coloração castanhoavermelhada e alas adaxiais castanho-claras.

Espécie terrícola, observada no interior da floresta em locais sombreados com solo encharcado. Ocorre em Guadalupe, Guatemala, Panamá, Colômbia, Venezuela, Guiana, Suriname, Guiana Francesa, Peru, Bolívia, Paraguai e no Brasil: AC, AM, AP, BA, ES, GO, MG, MT, PA, PE e SP (Kramer 1957).

Material examinado: F.F.F. Mazziero 1769 (BAUR).

22. Lindsaea lancea (L.) Bedd. var. lancea (Lindsaeaceae) Pode ser reconhecida na área de estudo por apresentar a maior parte do pecíolo e da raque castanho-claros a estramíneos, e ambas as faces da raque quadrangulares.

Espécie terrícola, observada no interior da floresta em locais sombreados com solo seco a encharcado. Apresenta ampla distribuição na região neotropical e no Brasil: AC, AM, BA, GO, MG, MS, MT, PA, PE, PR, RJ, RS, SC e SP (Kramer 1957).

Material examinado: F.F.F. Mazziero 1749 (BAUR).

23. Lindsaea quadrangularis Raddi subsp. terminalis K.U. Kramer (Lindsaeaceae)

É a única espécie do gênero, na área de estudo, a apresentar raque e pecíolo castanho-escuros a nigrescentes, com a raque quadrangular em ambas as faces, sem alas de coloração mais clara.

Espécie terrícola, encontrada no interior da floresta em locais sombreados e solo encharcado, mas também crescendo sobre pequenos morros e solo seco. Ocorre no Paraguai e no Brasil: BA, ES, GO, MG, PR, RJ, RS, SC e SP (Kramer 1957).

Material examinado: F.F.F. Mazziero 1748 (BAUR).

\section{Lomariocycas schomburgkii (Klotzsch) Gasper \& A.R.}

Sm. (Blechnaceae)

Separa-se das demais espécies da família Blechnaceae encontradas por apresentar escamas da base do pecíolo bicolores, com a porção central castanho-escura com a margem castanho-clara e frondes dimorfas.

Espécie terrícola, encontrada em locais abertos na borda da floresta, a pleno sol e solo encharcado ou não, crescendo junto a gramíneas. Ocorre na Costa Rica, Panamá, Colômbia, Venezuela, Guiana, Equador, Peru, Bolívia e no Brasil: AM, BA, DF, ES, GO, MG, PR, RJ, RS, SC e SP (Dittrich et al. 2018).

Material examinado: F.F.F. Mazziero 1795 (BAUR).

25. Lygodium volubile Sw. (Lygodiaceae)

Figura $4 \mathrm{~b}$ 

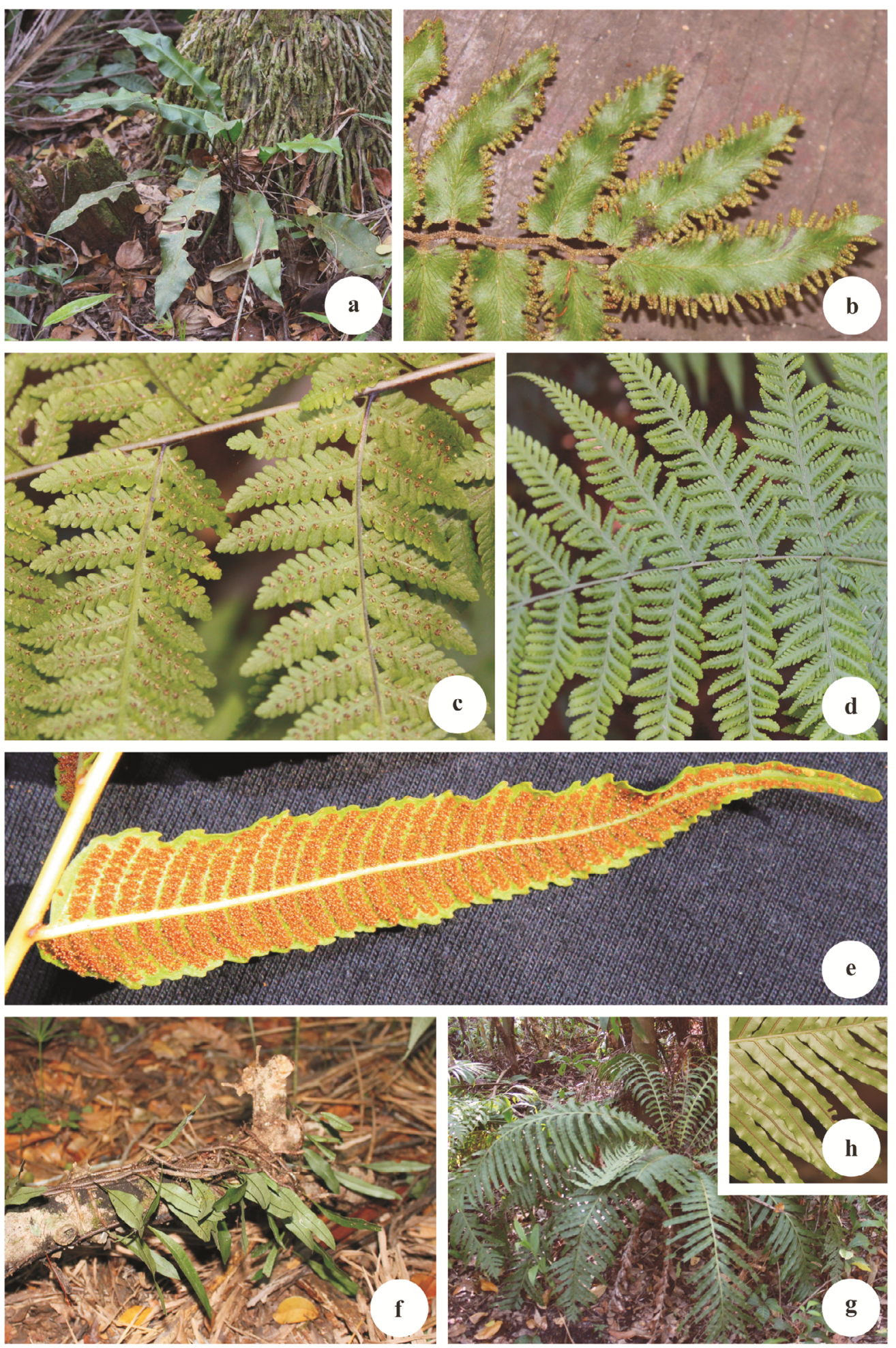

Figura 4. Espécies encontradas em área de floresta paludosa no Município de Dois Córregos, Estado de São Paulo, Brasil. a. Elaphoglossum luridum (Fée) Christ. a. hábito. b. Lygodium volubile Sw. b. pina fértil. c-d. Macrothelypteris torresiana (Gaudich.) Ching. c. superfície abaxial. d. superfície adaxial. e. Meniscium serratum Cav. e. superfície abaxial. f. Microgramma squamulosa (Kaulf.) de la Sota. f. hábito. g-h. Neoblechnum brasiliense (Desv.) Gasper \& V.A.O Dittrich. g. hábito. h. superfície abaxial.

Figure 4. Species found in a swamp forest area in Dois Córregos Municipality, São Paulo State, Brazil. a. Elaphoglossum luridum (Fée) Christ. a. habit. b. Lygodium volubile Sw. b. fertile pinna. c-d. Macrothelypteris torresiana (Gaudich.) Ching. c. abaxial surface. d. adaxial surface. e. Meniscium serratum Cav. e. abaxial surface. f. Microgramma squamulosa (Kaulf.) de la Sota. f. habit. g-h. Neoblechnum brasiliense (Desv.) Gasper \& V.A.O Dittrich. g. habit. h. abaxial surface. 
Espécie com hábito trepador, com as frondes se enrolando nos forófitos, sendo a única espécie da área que apresenta esta característica. Além disso, seus esporângios estão localizados em projeções na margem da lâmina.

Espécie volúvel, crescendo em locais sombreados na borda e no interior da floresta, em pontos de solo seco. Ocorre no México, Belize, Guatemala, Honduras, Nicarágua, Costa Rica, Panamá, Cuba, Jamaica, Trinidad, Colômbia, Venezuela, Guiana Francesa, Suriname, Guiana, Equador, Peru, Bolívia, Argentina e no Brasil: AC, AL, AM, AP, BA, CE, DF, ES, GO, MA, MG, MS, PA, PB, PE, PR, RJ, RN, RO, RR, RS, SC, SE, SP e TO (Prado \& Hirai 2010).

Material examinado: F.F.F. Mazziero 1786 (BAUR).

\section{Lytoneuron lomariaceum (Klotzsch) Yesilyurt} (Blechnaceae)

Dentre as espécies com soros marginais encontradas na área de estudo, é a única com lâmina simples, profundamente sulcada e pedada, com algumas incisões quase atingindo a costa.

Espécie terrícola, encontrada na borda da floresta, entre as gramíneas em locais sombreados. Ocorre na Guiana, Venezuela, Peru, Argentina, Paraguai e no Brasil: BA, DF, ES, GO, MG, MS, MT, PR, RJ, RS, SC e SP (Tryon 1942, Smith 1995, Torres et al. 2006).

Material examinado: F.F.F. Mazziero 1753 (BAUR).

\section{Macrothelypteris torresiana (Gaudich.) Ching} (Thelypteridaceae)

Figura $4 \mathrm{c}-\mathrm{d}$

Espécie com dois feixes vasculares na base do pecíolo, lâmina 2-3-pinado-pinatissecta, raque e costa não sulcados, diferindo assim de Lastreopsis amplissima e das demais espécies de Thelypteridaceae observadas na área de estudo.

Espécie terrícola, encontrada na borda e no interior da floresta, em locais ensolarados e solo úmido a encharcado. Espécie introduzida na região neotropical, sendo encontrada dos Estados Unidos até Bolívia, Paraguai, Argentina e no Brasil: AL, BA, CE, DF, ES, GO, MG, MS, MT, PB, PE, PR, RJ, RN, RO, RS, SC e SP (Smith 1992, Ponce 2007).

Material examinado: F.F.F. Mazziero 1777 (BAUR).

28. Meniscium arborescens Humb. \& Bonpl. ex Willd.

(Thelypteridaceae)

Separa-se das demais espécies de Meniscium observadas na área de estudo pelas pinas oblongo-lanceoladas, com a margem inteira a levemente crenulada, 9-13 aréolas entre a costa e a margem e soros, muitas vezes, confluentes na maturidade.

Espécie terrícola, encontrada a pleno sol na borda do fragmento, em locais com solo seco. Encontrada na Mesoamérica, Colômbia, Venezuela, Guiana, Suriname, Guiana Francesa, Equador, Peru, Paraguai e no Brasil: AC,
AM, AP, BA, DF, ES, GO, MA, MG, MS, MT, PA, PI, PR, RJ, RR, SE, SP e TO (Prado 2005, Ponce 2007).

Material examinado: F.F.F. Mazziero 2003 (BAUR).

\section{Meniscium chrysodioides Fée (Thelypteridaceae)}

Dentre as espécies deste gênero, observadas no presente estudo, Meniscium chrysodioides pode ser reconhecida pela presença de pinas largamente ovais, com 16-20 aréolas entre à costa e a margem na porção mais larga da pina, margem inteira e soros não confluentes na maturidade.

Espécie terrícola, observada no interior da floresta, nos pontos mais altos e com solo seco. Ocorre na Guiana, Equador, Venezuela, Bolívia e no Brasil: AC, AL, GO, MG, MS, PA, PE e SP (Smith 1992, Ponce 2007).

Material examinado: F.F.F. Mazziero 1761 (BAUR).

\section{Meniscium longifolium Desv. (Thelypteridaceae)}

Esta espécie apresenta pinas com tricomas aciculares, 2-3 mm de comprimento na face abaxial, margem inteira $\mathrm{e}$ soros não confluentes na maturidade, sendo, desta maneira, reconhecida dentre as demais espécies do gênero encontradas na área.

Espécie terrícola, observada na área de estudo nos pontos mais elevados do interior da floresta, em locais sombreados com solo seco. Ocorre na Venezuela, Colômbia, Equador, Bolívia e no Brasil: AC, AM, AP, BA, CE, DF, ES, MG, MT, MS, PA, PE, PR, RJ, RO, SC e SP (Salino \& Semir 2004b).

Material examinado: F.F.F. Mazziero 1762 (BAUR).

\section{Meniscium serratum Cav. (Thelypteridaceae)} Figura 4 e

Separa-se facilmente das espécies deste gênero encontradas na área de estudo, por apresentar pinas com a margem uncinado-serreada.

Espécie terrícola, observada no interior e na borda da floresta, em locais com solo seco a úmido, ensolarados ou sombreados. Encontrada em: Estados Unidos, Antilhas, México até o Panamá, Colômbia até Guianas, Bolívia, Argentina, Paraguai e no Brasil: AC, AL, AM, AP, BA, CE, DF, ES, GO, MA, MG, MS, MT, PA, PB, PE, PR, RJ, RO, SC, SE e SP (Smith 1992, Ponce 2007).

Material examinado: F.F.F. Mazziero 2004 (BAUR).

\section{Microgramma squamulosa (Kaulf.) de la Sota} (Polypodiaceae)

Figura $4 \mathrm{f}$

Separa-se das demais espécies de Polypodiaceae com a lâmina inteira pela presença de fronde hemidimorfa, com escamas esparsas e concentradas na costa abaxial, soros arredondados formando uma fileira entre a costa e a margem da lâmina.

Espécie epífita, encontrada crescendo sobre angiospermas no interior da floresta em locais sombreados. Apresenta 
distribuição geográfica para Peru, Paraguai, Argentina, Uruguai e no Brasil: BA, ES, MG, MS, PR, RJ, RS, SC e SP (Prado et al. 2010).

Material examinado: F.F.F. Mazziero 1785 (BAUR).

33. Neoblechnum brasiliense (Desv.) Gasper \& V.A.O. Dittrich (Blechnaceae)

Figura 4 g-h

Espécie reconhecida na área de estudo pela presença de caule subarborescente, escamas da base do pecíolo linearlanceoladas e nigrescentes, frondes monomorfas e base da lâmina gradualmente reduzida.

Espécie terrícola, encontrada por toda a área de estudo, em locais sombreados ou a pleno sol, com solo sempre encharcado. Ocorre em Guatemala, Colômbia, Venezuela, Equador, Peru, Bolívia, Paraguai, Argentina, Uruguai e no Brasil: BA, CE, DF, ES, GO, PE, PR, MG, MS, MT, RJ, RS, SE, SC e SP (Dittrich et al. 2017).

Material examinado: F.F.F. Mazziero 1751 (BAUR).

\section{Osmunda spectabilis Willd. (Osmundaceae)}

Trata-se de uma espécie facilmente reconhecida pela presença de frondes estéreis 2-pinadas e pelas frondes férteis hemidimorfas, apenas com a porção apical da fronde modificada, portando os esporângios.

Espécie terrícola, observada na borda da floresta em locais ensolarados e com solo encharcado. Ocorre no Canadá, Estados Unidos, México, Índias Ocidentais, Honduras, Costa Rica, Colombia, Venezuela, Equador, Peru, Bolívia, Paraguai, Uruguai e no Brasil: BA, DF, ES, GO, MG, MS, MT, PR, RJ, RS, SC e SP (Tryon \& Stolze 1989, Kessler $\&$ Smith 2017).

Material examinado: F.F.F. Mazziero 1787 (BAUR).

35. Osmundastrum cinnamomeum (L.) C. Presl (Osmundaceae)

Dentre as espécies observadas na área de estudo com frondes dimorfas, pode ser reconhecida pela fronde estéril 1-pinado-pinatissecta.

Espécie terrícola, encontrada no interior da floresta, crescendo à sombra e solo seco. Ocorre em: Ásia, Canadá, Estados Unidos, México, Mesoamérica, Grandes Antilhas, Bermudas, Colômbia, Venezuela, Equador, Peru e Paraguai (Schwartsburd \& Labiak 2007, Kessler \& Smith 2017). No Brasil é encontrada em: BA, ES, MG, PR, RJ, RS, SC e SP.

Material examinado: F.F.F. Mazziero 2005 (BAUR).

36. Palhinhaea cernua (L.) Franco \& Vasc. (Lycopodiaceae)

Única espécie de licófita observada na área de estudo e reconhecida pelos caules anisotomicamente ramificados, cobertos por microfilos, esporofilos agrupados formando um estróbilo e esporângios adaxiais.
Espécie terrícola, encontrada na borda do remanescente, exposta ao sol em solo úmido a encharcado. Apresenta distribuição pantropical e no Brasil: AC, AL, AM, AP, BA, CE, DF, ES, GO, MA, MG, MS, MT, PA, PB, PE, PR, RJ, RO, RR, RS, SC, SP e TO (Øllgaard \& Windisch 2016).

Material examinado: F.F.F. Mazziero 1737 (BAUR).

\section{Parablechnum cordatum (Desv.) Gasper \& Salino} (Blechnaceae)

Figura $5 \mathrm{a}-\mathrm{b}$

Separa-se das demais espécies da família Blechnaceae encontradas na área de estudo pelas escamas da base do pecíolo lanceoladas a ovais, castanho-claras, frondes dimorfas, sendo as frondes estéreis 1-pinadas.

Espécie terrícola, encontrada em locais com solo encharcado e a pleno sol, na borda da floresta. Pode ser encontrada na Guiana, Venezuela, Colômbia, Equador, Ilhas Juan Fernández, Ilhas Falkland, Chile, Bolívia, Peru, Paraguai, Argentina e no Brasil: BA, DF, ES, GO, MG, MT, PR, RJ, RS, SC e SP (Tryon \& Stolze 1993, Ditrich et al. 2018).

Material examinado: F.F.F. Mazziero 1752 (BAUR).

38. Pecluma robusta (Fée) M. Kessler \& A.R. Sm. (Polypodiaceae)

Entre as espécies da família Polypodiaceae encontradas na área de estudo, se assemelha mais a Serpocaulon vacillans, no entanto, difere por apresentar raque adaxial não sulcada e nervuras livres.

Espécie terrícola, encontrada no interior da floresta em local sombreado com solo úmido. Apresenta distribuição para Peru, Bolívia, Paraguai, Argentina e no Brasil: BA, CE, ES, MG, MS, PE, PR, RJ, RS, SC e SP (Smith et al. 2018).

39. Pityrogramma calomelanos (L.) Link (Pteridaceae) Figura $5 \mathrm{c}-\mathrm{d}$

Distingui-se das demais espécies do gênero encontradas na área por apresentar pinas basais 2-pinado-pinatissectas, pinas apicais pinatissectas e deltoides a lanceoladas.

Espécie terrícola, observada na borda da floresta crescendo em locais expostos ao sol com solo seco. Ocorre nos Estados Unidos, México, América Central, Antilhas, Colômbia, Venezuela, Guiana, Suriname, Guiana Francesa, Trinidad, Equador, Peru, Bolívia, Paraguai, Argentina e no Brasil: AC, AL, AM, AP, BA, CE, DF, ES, GO, MA, MG, MS, MT, PA, PB, PE, PI, PR, RJ, RN, RO, RR, RS, SE, SC, SP e TO (Nóbrega \& Prado 2008, Kessler et al. 2017).

Material examinado: F.F.F. Mazziero 1775 (BAUR).

40. Pityrogramma calomelanos (L.) Link x P. trifoliata (L.) R.M. Tryon (Pteridaceae)

Figura 5 e-f 

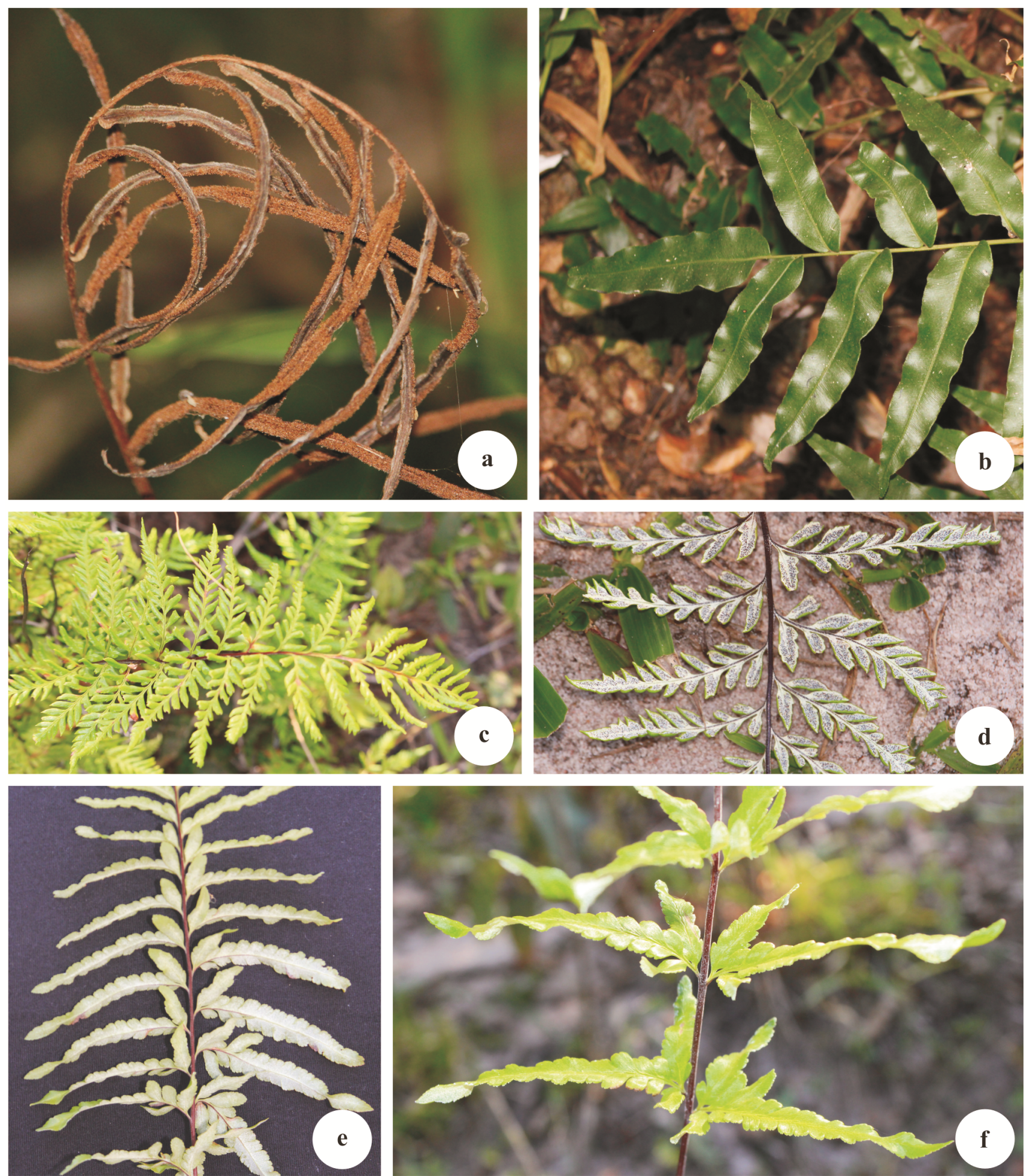

Figura 5. Espécies encontradas em área de floresta paludosa no Município de Dois Córregos, Estado de São Paulo, Brasil. a-b. Parablechnum cordatum (Desv.) Gasper \& Salino. a. fronde fértil. b. fronde estéril. c-d. Pityrogramma calomelanos (L.) Link. c. hábito. d. superfície abaxial. e-f. Pityrogramma calomelanos x Pityrogramma trifoliata. e. superfície abaxial. f. pinas proximais.

Figure 5. Species found in a swamp forest area in Dois Córregos Municipality, São Paulo State, Brazil. a-b. Parablechnum cordatum (Desv.) Gasper \& Salino. a. fertile frond. b. sterile frond. c-d. Pityrogramma calomelanos (L.) Link. c. habit. d. abaxial surface. e-f. Pityrogramma calomelanos x Pityrogramma trifoliata. e. abaxial surface. f. proximal pinna. 
Indivíduo com características da lâmina intermediária dos supostos parentais (P. calomelanos e P. trifoliata). Apresenta pinas proximais e medianas pinatífidas em sua maior parte, apenas com a porção basal 1-pinada e pinas distais pinatífidas e oblongas ( $v s$. em P. trifoliata as pinas proximais e medianas são 3-5-folioladas, segmentos inteiros e pinas distais inteiras e oblongas; em P. calomelanos as pinas proximais e medianas são 2-pinado a 2-pinado-pinatífidas e as distais pinatissectas e deltoides a lanceoladas). Tryon (1962) e Kessler et al. (2017) relatam a formação de híbridos entre estas duas espécies.

Foi encontrado na área de estudo como terrícola, crescendo na borda da floresta entre populações de $P$. calomelanos e P. trifoliata, a pleno sol.

Material examinado: F.F.F. Mazziero 2006 (BAUR).

41. Pityrogramma trifoliata (L.) R.M. Tryon (Pteridaceae)

Separa-se das demais espécies do gênero encontradas na área pela presença de pinas basais e medianas 3-5 folioladas, com segmentos oblongos e inteiros, enquanto as pinas distais são inteiras e oblongas.

Espécie terrícola, encontrada junto às gramíneas na borda da floresta, em locais expostos ao sol com solo seco. Ocorre nos Estados Unidos, México, América Central, Grandes Antilhas, Colômbia, Venezuela, Equador, Peru, Bolívia, Chile, Paraguai, Argentina, Chile e no Brasil: AC, DF, ES, GO, MG, MS, MT, PR, RJ, RS, SC e SP (Nóbrega \& Prado 2008, Kessler et al. 2017).

Material examinado: F.F.F. Mazziero 1790 (BAUR).

42. Pleopeltis astrolepis (Liebm.) E. Fourn. (Polypodiaceae) Figura $6 \mathrm{a}-\mathrm{b}$

Separa-se facilmente das demais espécies da família Polypodiaceae encontradas na área, pela fronde monomorfa, presença de escamas no tecido laminar abaxial e adaxial, soros oblongos formando uma fileira entre a costa e a margem.

Espécie epífita, observada sobre angiospermas no interior da floresta em locais sombreados. Ocorre nos Estados Unidos, México, Guatemala, Belize, Honduras, El Salvador, Nicarágua, Costa Rica, Panamá, Antilhas, Colômbia, Venezuela, Trinidad \& Tobago, Suriname, Guiana Francesa, Peru, Bolívia e no Brasil: Al, AP, BA, CE, ES, GO, MG, MS, PA, PB, PE, PR, RJ, RS, SE, SC e SP (Prado et al. 2010).

Material examinado: F.F.F. Mazziero 1740 (BAUR).

43. Pleopeltis hirsutissima (Raddi) de la Sota (Polypodiaceae)

Espécie separada das demais espécies de Pleopeltis ocorrentes na área de estudo pelo caule curto-reptante, lâmina pinatífida a pinada, com mais de 20 pares de segmentos/ pinas, tecido laminar adaxial e abaxial densamente escamoso e segmentos/pinas patentes, além da presença de um aeróforo na aurícula acroscópica.

Espécie epífita, crescendo sobre angiospermas na borda da floresta em local ensolarado. Ocorre em Bolívia, Argentina, Paraguai, Uruguai e no Brasil: AL, AM, BA, DF, ES, GO, MG, MS, MT, PE, PI, PR, RJ, RO, RS, SC e SP (Assis \& Labiak 2009, Prado et al. 2010).

Material examinado: F.F.F. Mazziero 1794 (BAUR).

44. Pleopeltis minima (Bory) J. Prado \& R.Y. Hirai (Polypodiaceae)

Apresenta caule longo-reptante, frondes com até $12 \mathrm{~cm}$ de comprimento, lâmina pectinada, com 10-12 segmentos, patentes a levemente arqueados, sem aeróforos, sendo separada assim das demais espécies do gênero observadas na área.

Espécie epífita, observada sobre angiospermas no interior e na borda da floresta e expostos ou não ao sol. Encontrada em: Bolívia, Argentina, Paraguai, Uruguai e no Brasil: ES, MG, MS, PR, RJ, RS, SC e SP (Assis \& Labiak 2009, Smith et al. 2018).

Material examinado: F.F.F. Mazziero s.n. (BAUR).

45. Pleopeltis pleopeltifolia (Raddi) Alston (Polypodiaceae) Figura $6 \mathrm{c}$

Facilmente reconhecida, em comparação com as espécies de Pleopeltis observadas neste estudo pela presença de caule curto-reptante, frondes pinatífidas a pinadas, com 7-8 segmentos, fortemente arqueados, formando um ângulo agudo em relação à raque.

Espécie epífita, observada sobre angiospermas no interior e na borda da floresta em locais sombreados. Ocorre na Bolivia, Argentina, Paraguai, Uruguai e no Brasil: BA, ES, MG, MS, PE, PR, RJ, RS, SC e SP (Schwartsburd \& Labiak 2007, Prado et al. 2010, Smith et al. 2018).

Material examinado: F.F.F. Mazziero 1745 (BAUR).

46. Pteridium esculentum (Kaulf.) Maxon (Dennstaedtiaceae) Separa-se de Hypolepis repens, a única outra espécie da família Dennstaedtiaceae observada na área de estudo, pelo pecíolo e raque inermes, lâmina coriácea e soros irrigados por várias nervuras.

Espécie terrícola, observada na borda da floresta, a pleno sol e solo seco. Apresenta distribuição por todo hemisfério sul, não sendo encontrada apenas na Africa (Schwartsburd et al. 2018). No Brasil: AC, AL, AP, AM, BA, CE, DF, ES, GO, MA, MG, MS, MT, PI, PA, PB, PE, PR, RJ, RN, RO, RR, RS, SC, SE, SP e TO.

Material examinado: F.F.F. Mazziero 1793 (BAUR).

47. Salvinia auriculata Aubl. (Salviniaceae)

Única espécie com hábito aquático e flutuante observada no presente estudo, além disso, pode ser reconhecida pela 
presença de frondes divididas em uma parte flutuante, com 2-3 cm de comprimento, oval a orbicular, e uma parte submersa altamente ramificada.

Espécie aquática flutuante, encontrada na área de estudo crescendo nos córregos, próxima às margens, a pleno sol. Esta espécie apresenta ampla distribuição na região neotropical e no Brasil: AL, AM, AP, BA, CE, DF, ES, MA, MG, MS, MT, PA, PB, PE, PI, PR, RJ, RN, RR, RS, SC, SE, SP e TO (Miranda \& Schwartsburd 2016).

Material examinado: F.F.F. Mazziero 1784 (BAUR)
48. Serpocaulon catharinae (Langsd. \& Fisch.) A.R. Sm. (Polypodiaceae)

Dentre as espécies de Serpocaulon encontradas na área de estudo, distingui-se pela presença de caule pruinoso, lâmina pinatissecta, glabrescente e uma fileira de soros por segmento.

Espécie epífita, crescendo sobre angiosperma no interior da floresta, em locais sombreados e úmidos. Ocorre no Paraguai, na Argentina, no Uruguai e no Brasil: AL, BA, ES, MG, PB, PE, PR, RJ, RS, SC e SP (Labiak \& Prado 2008).
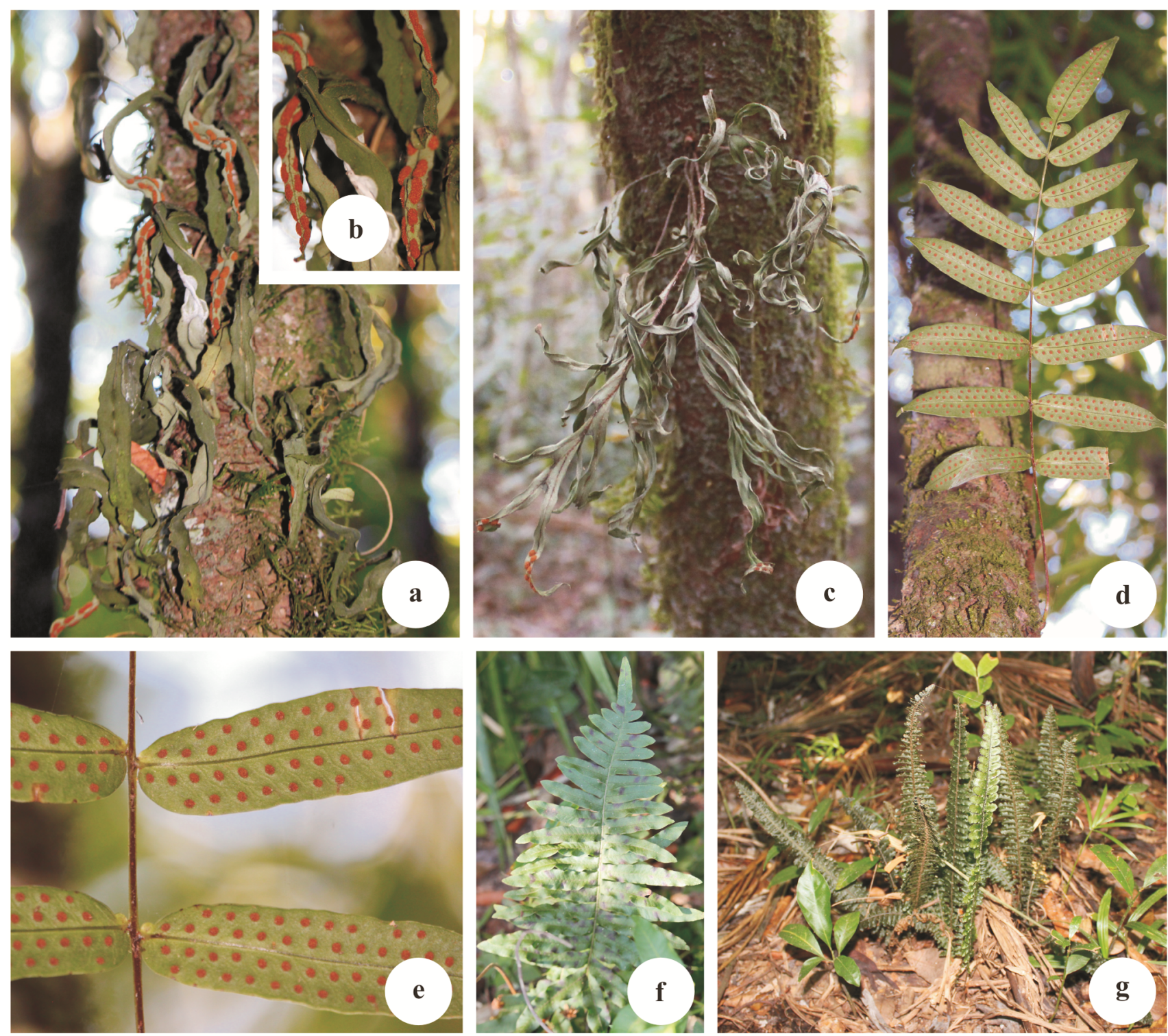

Figura 6. Espécies encontradas em área de floresta paludosa no Município de Dois Córregos, Estado de São Paulo, Brasil. a-b. Pleopeltis astrolepis (Liebm.) E. Fourn. a. hábito. b. fronde fértil. c. Pleopeltis pleopeltifolia (Raddi) Alston. c. hábito. d-e. Serpocaulon fraxinifolium (Jacq.) A.R. Sm. d. hábito. e. pinas medianas. f. Serpocaulon vacillans (Link) A.R. Sm. hábito. g. Trichomanes cristatum Kaulf. hábito.

Figure 6. Species found in a swamp forest area in Dois Córregos Municipality, São Paulo State, Brazil. a-b. Pleopeltis astrolepis (Liebm.) E. Fourn. a. habit. b. fertile frond. c. Pleopeltis pleopeltifolia (Raddi) Alston. c. habit. d-e. Serpocaulon fraxinifolium (Jacq.) A.R. Sm. d. habit. e. medial pinnae. f. Serpocaulon vacillans (Link) A.R. Sm. habit. g. Trichomanes cristatum Kaulf. habit. 
Material examinado: F.F.F. Mazziero 1744 (BAUR).

49. Serpocaulon fraxinifolium (Jacq.) A.R. Sm. (Polypodiaceae)

Figura 6 d-e

Pode ser reconhecida entre as espécies do gênero encontradas na área de estudo por apresentar a porção basal e mediana da lâmina 1-pinada e 3-4 fileiras de soros por pina.

Espécie epífita, encontrada sobre angiospermas no interior da mata, em locais úmidos e sombreados. Ocorre em quase todos os países da região neotropical e no Brasil: ES, MG, PR, RJ, SC e SP (Labiak \& Prado 2008).

Material examinado: F.F.F. Mazziero 1750 (BAUR).

50. Serpocaulon vacillans (Link) A.R. Sm. (Polypodiaceae) Figura $6 \mathrm{f}$

Apresenta lâmina pinatissecta com a face abaxial apresentando tricomas e escamas lineares e 1-2 fileiras de soros por segmento, diferindo assim das espécies do gênero observadas neste estudo.

Espécie terrícola, encontrada na borda da floresta em pontos sombreados com solo seco. Ocorre na Bolívia, Argentina, Paraguai e no Brasil: MG, PR, RJ, RS, SC e SP (Assis \& Labiak 2009, Smith et al. 2018).

Material examinado: F.F.F. Mazziero 1781 (BAUR).

51. Sticherus lanuginosus (Fée) Nakai (Gleicheniaceae)

Separa-se das demais espécies da família Gleicheniaceae observadas na área de estudo pela ausência de pinas acessórias, gemas cobertas por escamas nas bifurcações e face abaxial densamente coberta por escamas.

Espécie terrícola observada na borda do remanescente crescendo junto a Dicranopteris flexuosa, em locais com solo seco e a pleno sol. Ocorre em: Costa Rica, Hispaniola, Colômbia, Venezuela, Equador, Peru, Bolívia, Paraguai e no Brasil pode ser encontrada em BA, DF, ES, GO, MG, PR, RJ, RS, SC e SP (Lima \& Salino 2018).

Material examinado: F.F.F. Mazziero 1733 (BAUR).

52. Trichomanes anadromum Rosenst. (Hymenophyllaceae)

Dentre as espécies da família Hymenophylaceae observadas na área se assemelha a Trichomanes polypodioides, que apresenta venação catádroma e os invólucros apicais, enquanto em T. anadromum a venação é anádroma e os invúlucros axiliares.

Espécie epífita, observada sobre samambaia arborescente (Cyathea atrovirens e C. delgadoi), no interior da floresta em local sombreado. Ocorre no Paraguai e no Brasil: ES, GO, MG, PR, RJ, RS, SC e SP (Windisch 2014).

Material examinado: F.F.F. Mazziero 1735 (BAUR).

53. Trichomanes cristatum Kaulf. (Hymenophyllaceae) Figura $6 \mathrm{~g}$
Difere das demais espécies de Trichomanes observadas na área de estudo por ser terrícola, apresentar o caule curtoreptante, com as frondes eretas e pectinadas.

Espécie terrícola, encontrada no interior da floresta em locais sombreados com solo encharcado. Ocorre em Colômbia, Venezuela, Equador, Peru, Bolívia, Paraguai, Argentina e no Brasil: AL, AM, AP, BA, DF, ES, GO, MA, MG, MS, MT, PA, PB, PE, PI, PR, RJ, RS, SC, SE, SP e TO (Windisch 1992b).

Material examinado: F.F.F. Mazziero 1742 (BAUR).

\section{Trichomanes polypodioides L. (Hymenophyllaceae)}

Espécie semelhante a T. anadromum, suas diferenças podem ser vistas nos comentários desta (item 52).

Espécie epífita, observada sobre Cyathea atrovirens e C. delgadoi, no interior da floresta em locais sombreados e úmidos. Ocorre em: México, Guatemala, Belize, Honduras, Nicarágua, Costa Rica, Panamá, Grandes e Pequenas Antilhas, Trinidad, Colômbia, Venezuela, Guiana, Suriname, Guiana Francesa, Equador, Peru, Bolívia, Paraguai, Uruguai e no Brasil: AP, BA, DF, ES, GO, MA, MG, MS, MT, PE, PI, PR, RJ, RS, SC e SP (Hirai \& Prado 2011, Windisch 2014).

Material examinado: F.F.F. Mazziero 1791 (BAUR).

O número de espécies encontradas no presente estudo é próximo a valores observados em outras áreas de floresta paludosa na porção central do Estado de São Paulo (Salino \& Joly 2001, Nóbrega \& Prado 2008, Mazziero \& Nonato 2015). As famílias com maior representatividade foram Thelypteridaceae com 13 espécies $(24,1 \%)$, seguida de Polypodiaceae com 10 espécies $(18,5 \%)$ e Blechnaceae, Dryopteridaceae e Pteridaceae com quatro espécies cada $(7,4 \%)$. Foram registrados 33 gêneros, sendo Amauropelta (5 spp.), Meniscium (4 spp.) e Pleopeltis (4 spp.) os que apresentaram maior número de espécies, representando, juntos, $24,1 \%$ do total encontrado. Estes resultados são semelhantes a diversos outros estudos realizados no interior paulista (i.e. Salino 1996, Salino \& Joly 2001, Nóbrega \& Prado 2008, Mazziero \& Nonato 2015), além disso, estas famílias figuram entre as mais diversas do Brasil (Prado et al. 2015).

Quanto às guildas de formas de vida, 41 espécies $(75,9 \%)$ são ervas terrícolas, nove são epífitas $(16,7 \%)$, duas são arborescentes $(3,7 \%)$ e apenas uma espécie é aquática e uma é volúvel (1,9\%, cada). A forma de vida terrícola é predominante no Brasil (Prado et al. 2015), o que resulta no domínio deste grupo em diversas fitofisionomias (Salino 1996, Nóbrega \& Prado 2008, Matos et al. 2010, Michelon \& Labiak 2013, Mazziero \& Nonato 2015, Mazziero et al. 2015, Schwartsburd et al. 2017). O baixo número de epífitas nas matas do interior paulista (Salino \& Joly 2001, Nóbrega \& Prado 2008, Mazziero \& Nonato 2015) pode estar relacionado com a sazonalidade marcante encontrada nestas áreas, como observado por Souza et al. (2012), para áreas de floresta estacional semidecidual de Minas Gerais. 
As espécies com distribuição geográfica neotropical (24 spp. $-44,4 \%$ ) são as mais comuns na área de estudo, seguidas pelas espécies endêmicas da América do Sul (20 spp. - 37\%), pantropicais (quatro espécies $-7,4 \%$ ), endêmicas do Brasil (duas espécies -3,7\%) e exóticas (três espécies - 5,6\%). O suposto híbrido Pityrogramma calomelanos x P. trifoliata apresenta distribuição desconhecida (1,9\%). Estes resultados são semelhantes a outros do interior paulista (Salino \& Joly 2001, Nóbrega \& Prado 2008, Mazziero \& Nonato 2015). As espécies exóticas encontradas já são amplamente distribuídas pelo Brasil e habitam, geralmente, em pontos que apresentam distúrbios causados pela ação antrópica. Todas as espécies observadas apresentam ampla distribuição geográfica, mesmo as endêmicas do Brasil. O predomínio destas plantas na área de estudo pode estar relacionado a homogeneidade ambiental das florestas paludosas e a sazonalidade da região, possibilitando que apenas espécies tolerantes a essas condições se desenvolvam.

Inventários de flora arbórea ou arbustivo-arbórea nos remanescentes de floresta paludosa do interior do Estado de São Paulo evidenciaram a riqueza destes grupos variando entre 36 e 61 espécies (Toniato et al. 1998, Paschoal \& Cavassan 1999, Teixeira \& Assis 2005, 2009), enquanto para as samambaias e licófitas a riqueza varia entre 45 e 55 espécies (Salino \& Joly 2001, Nóbrega \& Prado 2008, Mazziero \& Nonato 2015, presente estudo). Estes valores são próximos e sugerem uma maior representatividade para este grupo de plantas para áreas de floresta paludosa, em comparação com o sugerido por Gentry (1990) e Costa (2004) para áreas de floresta tropical. No entanto, mais estudos nestas formações são necessários, para melhor compreender a representatividade das samambaias e licófitas em florestas paludosas.

Portanto, é evidente a importância da conservação e proteção dos remanescentes de floresta paludosa para as samambaias e licófitas, pois estas áreas apresentam composição e riqueza de espécies distintas das observadas em outras formações florestais do interior paulista.

\section{Agradecimentos}

Os autores agradecem aos proprietários do Pesqueiro Jussara, por permitirem a realização deste estudo. Somos gratos também aos revisores anônimos, pelas valiosas contribuições para melhoria deste manuscrito.

\section{Literatura citada}

Alvares, C.A., Stape, J.L., Sentelhas, P.C., Gonçalves, J.L.M. \& Sparovek, G. 2014. Köppen's climate classification map for Brazil. Meteorologische Zeitschrift 22: 711-728.
Assis, E.L.M. \& Labiak, P.H. 2009. Polypodiaceae da borda oeste do Pantanal sul-matogrossense, Brasil. Brazilian Journal of Botany 32: 233-247.

Athayde-Filho, F.P., Pereira, V.S., Smidt, E.C. \& Nonato, F.R. 2003. Pteridófitas do Parque Estadual da Ilha Anchieta (PEIA). Bradea 9: 55-66.

Biral, L. \& Prado, J. 2012. First record of Pellaea ovata (Pteridaceae) from Brazil. American Fern Journal 102: 83-85.

Boldrin, A.H.L. \& Prado, J. 2007. Pteridófitas terrestres e rupícolas do forte das Andradas, Guarujá, São Paulo, Brasil. Boletim Botânico da Universidade de São Paulo 25: 1-69.

Climate-data. 2019. Climate-Data.Org: Clima Dois Córregos. Disponível em https://pt.climate-data.org/ america-do-sul/brasil/sao-paulo/dois-corregos-34941/ (acesso em 25-VI-2019).

Colli, A.M.T., Souza, S.A. \& Silva, R.T. 2003. Pteridófitas do Parque Estadual de Porto Ferreira (SP), Brasil. Revista do Instituto Florestal 15: 29-35.

Colli, A.M.T., Salino, A., Lucca, A.L.T. \& Silva, R.T. 2004a. Pteridófitas do Parque Estadual da Vassununga, Santa Rita do Passa Quatro (SP), Brasil. Capetinga Leste e Capetinga Oeste. Revista do Instituto Florestal 16: 25-30.

Colli, A.M.T., Souza, S.A., Salino, A., Lucca, A.L.T. \& Silva, R.T. 2004b. Pteridófitas do Parque Estadual da Vassununga, Santa Rita do Passa Quatro (SP), Brasil. Gleba do Pé-Gigante. Revista do Instituto Florestal 16: 121-127.

Colli, A.M.T., Salino, A., Rodriguez Neto, E.J., Estevan, E.C. \& Robinato, A. 2007. Pteridófitas da Reserva Estadual de Águas da Prata, SP. Revista Logos 15: 11-18.

Costa, F.R.C. 2004. Structure and composition of the ground-herb community in a terra-firme Central Amazonian forest. Acta Amazonica 34: 53-59.

Dittrich, V.A.O., Salino, A. \& Monteiro, R. 2015. The Blechnum occidentale (Blechnaceae, Polypodiopsida) species group in southern and southeastern Brazil. Phytotaxa 231: 201-229.

Dittrich, V.A.O., Salino, A., Monteiro, R. \& Gasper, A.L. de. 2017. The family Blechnaceae (Polypodiopsida) in Brazil: Key to the genera and taxonomic treatment of Austroblechnum, Cranfillia, Lomaridium, Neoblechnum and Telmatoblechnum for southern and southeastern Brazil. Phytotaxa 303: 1-33.

Dittrich, V.A.O., Salino, A., Monteiro, R. \& Gasper, A.L.de. 2018. The fern genera Lomaria, Lomariocycas, and Parablechnum (Blechnaceae, Polypodiopsida) in southern and southeastern Brazil. Phytotaxa 362: 245262. 
Filgueiras, T.S., Nogueira, P.E., Brochado, A.L. \& Guala II, G.F. 1994. Caminhamento: um método expedito para levantamentos florísticos qualitativos. Caderno de Geociências 12: 39-43.

Flora do Brasil 2020 em construção. Jardim Botânico do Rio de Janeiro. Disponível em http://floradobrasil.jbrj. gov.br/ (acesso em 05-XII-2019).

Gentry, A.H. 1990. Floristic similarities and differences between Southern Central America and upper Central Amazonia. In: A.H. Gentry (ed.), Four neotropical rain forests. Yale University Press, New Haven, pp. 141-160.

Hirai, R.Y. \& Prado, J. 2011. Criptógamos do Parque Estadual das Fontes do Ipiranga, São Paulo, SP. Pteridophyta: 10. Hymenophyllaceae. Hoehnea 38: 501-510.

Hirai, R.Y. \& Prado, J. 2012. Criptógamos do Parque Estadual das Fontes do Ipiranga, São Paulo, SP. Pteridophyta: 7. Dryoperidaceae e 11. Lomariopsidaceae. Hoehnea 39: 555-564.

Ivanauskas, N.M., Rodrigues, R.R. \& Nave, A.G. 1997. Aspectos ecológicos de um trecho de floresta de brejo em Itatinga, SP: florística, fitossociologia e seletividade de espécies. Revista Brasileira de Botânica 20: 139-150.

Kessler, M. \& Smith, A.R. 2017. Prodromus of a fern flora for Bolivia. IX. Osmundaceae. Phytotaxa 273: 175-182.

Kessler, M., Smith, A.R. \& Prado, J. 2017. Prodromus of a fern flora for Bolivia. XXVII. Pteridaceae. Phytotaxa 332: 201-250.

Kessler, M., Moran, R.C., Mickel, J.T., Matos, F.B. \& Smith, A.R. 2018. Prodromus of a fern flora for Bolivia. XXXV. Dryopteridaceae. Phytotaxa 353: 1-114.

Kramer, K.U. 1957. A revision of the genus Lindsaea in the New World with notes on allied genera. Acta Botanica Neerlandica 6: 97-290.

Labiak, P.H. \& Prado, J. 2008. New combinations in Serpocaulon and provisional key for the Atalntic Rain Forest species. American Fern Journal 98: 139-159.

Lehnert, M. 2016. A synopsis of the exindusiate species of Cyathea (Cyatheaceae - Polypodiopsida) with bipinnatepinnatifid or more complex fronds, with revision of the C. lasiosora complex. Phytotaxa 243: 1-53.

Lehnert, M. \& Kessler, M. 2018. Prodromus of a fern flora for Bolivia. XX. Cyatheaceae. Phytotaxa 334: 118-134.

Lima, L.V. \& Salino, A. 2018. The fern family Gleicheniaceae (Polypodiopsida) in Brazil. Phytotaxa 358: 199-234.

Marques, M.C.M., Silva, S.M. \& Salino, A. 2003. Florística e estrutura do componente arbustivo-arbóreo de uma floresta higrófila da bacia do Rio Jacaré-Pepira, SP, Brasil. Acta Botanica Brasilica 17: 495-506.

Matos, F.B., Amorim, A.M. \& Labiak, P.H. 2010. The ferns and lycophytes of a montane tropical forest of Southern Bahia, Brazil. Journal of Botanical Research Institute 4: 333-346.
Mazziero, F.F.F. \& Nonato, F.R. 2015. Ferns and lycophytes from Jaú, São Paulo, Brazil. Checklist 11: 1798.

Mazziero, F.F.F., Labiak, P.H. \& Paciencia, M.L.B. 2015. Checklist of Ferns and lycophytes from the Parque Estadual Turístico do Alto Ribeira, Iporanga, São Paulo, Brazil. Checklist 11: 1791.

Michelon, C. \& Labiak, P.H. 2013. Samambaias e licófitas do Parque Estadual do Guartelá. Hoehnea 40: 191-204.

Mickel, J.T. 1991. Elaphoglossum and Peltapteris. In: R.M. Tryon \& R.G. Stolze (eds.), Pteridophyta of Peru, Part IV, 17. Dryopteridaceae. Fieldiana Botany New Series 27: 111-170.

Miranda, C.V. \& Schwartsburd, P.B. 2016. Aquatic ferns from Viçosa (MG: Brazil): Salviniales (Filicopsida; Tracheophyta). Brazilian Journal of Botany 39: 935-942.

Mynssen, C.M. 2011. Woodsiaceae (Hook.) Herter (Polypodiopsida) no Estado do Rio Grande do Sul, Brasil. Pesquisas: Botânica 62: 273-298.

Nóbrega, G.A. \& Prado, J. 2008. Pteridófitas da vegetação nativa do Jardim Botânico Municipal de Bauru, Estado de São Paulo, Brasil. Hoehnea 35: 7-55.

Nóbrega, G.A., Aidar, M.P.M., Paciencia, M.L.B. \& Prado, J. 2016. Identification key for lycophytes and ferns from the Picinguaba and Santa Virginia Nuclei, Parque Estadual da Serra do Mar, Ubatuba, SP, Brazil. Biota Neotropica 16: 1-15.

Øllgaard, B. \& Windisch, P.G. 2016. Lycopodiaceae in Brazil. Conspectus of the family II: the genera Lycopodiella, Palhinhaea and Pseudolycopodiella. Rodriguésia 67: 691-719.

Paciencia, M.L.B. 2008. Diversidade de pteridófitas em gradientes de altitude na Mata Atlântica do Estado do Paraná. Tese de Doutorado, Universidade de São Paulo, São Paulo.

Paschoal, M.E.S. \& Cavassan, O. 1999. A flora arbórea da mata de brejo do Ribeirão do Pelintra, Agudos - SP. Naturalia 24: 171-191.

Pietrobom, M.R., Windisch, P.G. \& Kieling-Rubio, M.A. 2012. Diversidade de filicíneas e licófitas na região do Pontal do Paranapanema (Estado de São Paulo) e efeito de impacto ambiental. Pesquisas, Botânica 63: 141-148.

Ponce, M. 1995. Las especies austrobrasileñas de Thelypteris subg. Amauropelta (Thelypteridaceae - Pteridophyta). Darwiniana 33: 257-283.

Ponce, M. 2007. Sinopsis de las Thelypteridaceae de Brasil central y Paraguay. Hoehnea 34: 283-333.

Ponce, M., Kieling-Rubio, M.A. \& Windisch, P.G. 2013. The genus Thelypteris (Thelypteridaceae, Polypodiopsida) in the State of Mato Grosso, Brazil - II - Subgenera Amauropelta (Kunze) A.R. Sm., Cyclosorus (Link) C.V. Morton and Steiropteris (C. Chr.) K. Iwats. Acta Botanica Brasilica 27: 597-603. 
Poulsen, A.D. 1996. Species richness and density of ground herbs within a plot of lowland rainforest in north-west Borneo. Journal of Tropical Ecology 12: 177-190.

PPG I. 2016. A community-derived classification for extant lycophytes and ferns. Journal of Systematics and Evolution 54: 563-603.

Prado, J. 1998. Pteridófitas do Estado de São Paulo. In: C.E. de M. Bicudo \& G.J. Shepherd (eds.), Fungos macroscópicos e plantas do Estado de São Paulo (Série Biodiversidade do Estado de São Paulo). FAPESP, São Paulo, pp. 49-61.

Prado, J. 2005. Flora da Reserva Ducke, Amazônia, Brasil: Pteridophyta - Thelypteridaceae. Rodrigésia 56: 105107.

Prado, J. \& Hirai, R.Y. 2010. Criptógamos do Parque Estadual das Fontes do Ipiranga, São Paulo, SP. Pteridophyta: 4. Davalliaceae, 19. Schizaeaceae, 23. Vittariaceae e 24. Woddsiaceae. Hoehnea 37: 791-800.

Prado, J. \& Hirai, R.Y. 2011. Checklist das licófitas e samambaias do Estado de São Paulo, Brasil. Biota Neotrópica 11: 161-190.

Prado, J. \& Labiak, P.H. 2009. Pteridófitas. In: M.I.M.S. Lopes, M. Kirizawa \& M.M. da R.F. de Melo (eds.), Patrimônio da Reserva Biológica do Alto da Serra de Paranapiacaba: a antiga Estação Biológica do Alto da Serra. Instituto de Botânica, São Paulo, pp. 269-289.

Prado, J., Hirai, R.Y. \& Schwartsburd, P.B. 2010. Criptógamos do Parque Estadual das Fontes do Ipiranga, São Paulo, SP. Pteridophyta: 9. Grammitidaceae e 16. Polypodiaceae. Hoehnea 37: 445-460.

Prado, J., Sylvestre, L.S., Labiak, P.H., Windisch, P.G., Salino, A., Barros, I.C.L., Hirai, R.Y., Almeida, T.E., Santiago, A.C.P., Kieling-Rubio, M.A., Pereira, A.F.N., Øllgaard, B., Ramos, C.G.V., Mickel, J.T., Dittrich, V.A.O., Mynssen, C.M., Schwartsburd, P.B., Condack, J.P., Pereira, J.B.S. \& Matos, F.B. 2015. Diversity of ferns and lycophytes in Brazil. Rodriguésia 66: 1-11.

Salino, A. 1996. Levantamento das Pteridófitas da Serra do Cuscuzeiro, Analândia, SP, Brasil. Revista Brasileira de Botânica 19: 173-178.

Salino, A. \& Joly, C.A. 2001. Pteridophytes of three remnants of gallery forests in the Jacaré-Pepira River basin, São Paulo state, Brazil. Boletim do Herbário Ezechias Paulo Heringer 8: 5-15.

Salino, A. \& Semir, J. 2004a. Thelypteris subg. Amauropelta (Thelypteridaceae - Pteridophyta) no Estado de São Paulo, Brasil. Lundiana 5: 83-112.

Salino, A. \& Semir, J. 2004b. Thelypteris subg. Meniscium (Thelypteridaceae - Pteridophyta) no Estado de São Paulo, Brasil. Braz. J. Bot. 27: 103-114.

Salino, A. \& Almeida, T.E. 2008. Pteridófitas do Parque Estadual do Jacupiranga, SP, Brasil. Acta Botanica Brasilica 22: 983-991.
Santiago, A.C.P. \& Almeida, T.E. Schizaeaceae in Flora do Brasil 2020 em construção. Jardim Botânico do Rio de Janeiro. Disponível em http://floradobrasil.jbrj.gov.br/ reflora/floradobrasil/FB92037 (acesso em 07-III-2020).

Scarano, F.R. 2006. Plant community structure and function in a swamp forest within the Atlantic rain forest complex: a synthesis. Rodriguésia 57: 491-502.

Scarano, F.R., Ribeiro, K.T., Moraes, L.F.D. \& Lima, H.C. 1997. Plant stablishment on flooded and unflooded patches of a freshwater swamp forest in southeastern Brazil. Journal of Tropical Ecology 14: 793-803.

Scarano, F.R., Rios, R.I. \& Esteves, F.A. 1998. Tree species richness, diversity and flooding regime: case studies of recuperation after anthropic impact in Brazilian foodprone forests. International Journal of Ecology and Environmental Sciences 24: 223-235.

Schwartsburd, P.B. \& Labiak, P.H. 2007. Pteridófitas do Parque Estadual de Vila Velha, Paraná, Brasil. Hoehnea 34: 159-209.

Schwartsburd, P.B. \& Prado, J. 2016. A taxonomic revision of the South American species of Hypolepis (Dennstaedtiaceae), Part II. American Fern Journal 106: $1-53$.

Schwartsburd, P.B., Yañez, A. \& Prado, J. 2018. Formal recognition of six subortinate taxa within the South American bracken fern, Pteridium esculentum ( $P$. esculentum subsp. arachnoideum s.l. - Dennstaedtiaceae), based on morphology and geography. Phytotaxa 333: 22-40.

Schwartsburd, P.B., Miranda, C.V., Pena, N.T.L., Oliveira, M.H., Silva, R.V. \& Marcolino, F. 2017. Checklist of Ferns and lycophytes from Parque Estadual Mata das Flores, Castelo, Espírito Santo, Brazil. Checklist 13: 621-633.

SIFESP. 2009. Mapa florestal dos municípios do Estado de São Paulo: Dois Córregos. Disponível em http://s. ambiente.sp.gov.br/sifesp/doiscorregos.pdf (acesso em 20-VI-2019).

Silva, F.D., Athayde-Filho, F.P. \& Windisch, P.G. 2015. Schizaeaceae (Polypodiopsida) no Estado do Mato Grosso, Brasil. Pesquisas, Botânica 68: 107-118.

Smith, A.R. 1986. Revision of the Neotropical fern genus Cyclodium. American Fern Journal 76: 56-98.

Smith, A.R. 1992. Thelypteridaceae. In: R.M. Tryon \& R.G. Stolze, R. G. (eds.), Pteridophyta of Peru. Part III. Fieldiana Botany New Series, 29:1-80.

Smith, A.R. 1995. Pteridophytes. In: P.E. Berry, B.K. Holst \& K. Yatskievych (eds.), Flora of the Venezuelan Guayana 2. Pteridophytes, Spermatophytes: Acanthaceae-Araceae. Timber Press, Portland pp. 1-706.

Smith, A.R. \& Kessler, M. 2017. Prodromus of a fern flora for Bolivia. XXX. Thelypteridaceae. Phytotaxa 331: 1-34. 
Smith, A.R., Kessler, M., León, B., Almeida, T.E., Jiménez-Pérez, I. \& Lehnert, M. 2018. Prodromus of a fern flora for Bolivia. XL. Polypodiaceae. Phytotaxa 354: 1-67.

Souza, F.S., Salino, A., Viana, P.L. \& Salimena, F.R.G. 2012. Pteridófitas da Serra Negra, Minas Gerais, Brasil. Acta Botanica Brasilica 26: 378-390.

Teixeira, A.P. \& Assis, M.A. 2005. Caracterização florística e fitossociológica do componente arbustivo-arbóreo de uma floresta paludosa no Município de Rio Claro (SP), Brasil. Revista Brasileira de Botânica 28: 467-476.

Teixeira, A.P. \& Assis, M.A. 2009. Relação entre heterogeneidade ambiental e distribuição de espécies em uma floresta paludosa no Município de Cristais Paulista, SP, Brasil. Acta Botanica Brasilica 23: 843853.

Teixeira, A.P. \& Assis, M.A. 2011. Floristic relationships among inland forest swamp forests of Southeastern and Central-Western Brazil. Brazilian Journal of Botany 34: 91-101.

Toniato, M.T.Z., Leitão-Filho, H.F \& Rodrigues, R.R. 1998. Fitossociologia de um remanescente de floresta higrófila (mata de brejo) em Campinas, SP. Revista Brasileira de Botânica 21: 127-210.

Torres, E.I.M., Ferrucci, M.S., Keller, H. \& Marquez, G.J. 2006. Presencia de Doryopteris lomariacea (Pteridaceae, Pteridophyta) em Argentina. Bonplandia 15: 143-148.
Torres, R.B., Matthes, L.A.F. \& Rodrigues, R.R. 1994. Florística e estrutura do componente arbóreo de mata de brejo em Campinas, SP. Revista Brasileira de Botânica 17: 189-194.

Tryon, R.M. 1942. A revision of the genus Doryopteris. Contributions of the Gray Herbarium of Harvard University 43: 1-80.

Tryon, R.M. 1962. Taxonomic fern notes. II. Pityrogramma (including Trismeria) and Anogramma. Contributions of the Gray Herbarium 189: 52-76.

Tryon, R.M. \& Stolze, R.G. 1989. Pteridophyta of Peru. Part I. 1. Ophioglossaceae - 12. Cyatheaceae. Fieldiana Botany New Series 20: 1-145.

Tryon, R.M. \& Stolze, R.G. 1993. Pteridophyta of Peru. Part V. 18. Aspleniaceae - 21. Polypodiaceae. Fieldiana Botany New Series 32: 1-208.

Weigand, A. \& Lehnert, M. 2016. The scaly tree ferns (Cyatheaceae - Polypodiopsida) of Brazil. Acta Botanica Brasilica 30: 336-350.

Windisch, P.G. 1992a. Pteridófitas da região norte-ocidental do Estado de São Paulo: guia para estudos e excursões. 2 ed. Universidade Estadual Paulista, São José do Rio Preto.

Windisch, P.G. 1992b. Trichomanes crispum L. (Pteridophyta, Hymenophyllaceae) and allied species. Bradea 6: 78-117.

Windisch, P.G. 2014. Hymenophyllaceae (Polypodiopsida) no Estado do Rio Grande do Sul. Pesquisas: Botânica 65: 15-48. 